\title{
Structurally-Defined Imidazolium-type Ionic Oligomers as Soluble/Solid Support for Peptide Synthesis
}

\author{
Supporting Information \\ Xun He and Tak Hang Chan ${ }^{*}$ \\ Department of Chemistry, McGill University, Montreal, Quebec, Canada H3A 2K6
}

\section{Experimental Section:}

General: All chemicals were obtained from Aldrich and used without further purification except otherwise indicated. Acetonitrile and dichloromethane were distilled from $\mathrm{CaH}_{2}$ as drying reagent. ${ }^{1} \mathrm{H}$ and ${ }^{13} \mathrm{C}$ NMR, COSY NMR spectra were recorded on Varian Mercury 300, 400, 800 and Unity 500 spectrometers equipped with Sun workstations. The chemical shifts were reported in parts per million on the $\delta$ scale referenced to residue $\mathrm{CHCl}_{3}$ at $\delta 7.24 \mathrm{ppm}, \mathrm{H}_{2} \mathrm{O}$ at $4.67 \mathrm{ppm}$ for ${ }^{1} \mathrm{H} \mathrm{NMR}$ and $\mathrm{CHCl}_{3}$ at $77.0 \mathrm{ppm}$ for ${ }^{13} \mathrm{C}$ NMR. The proton and carbon assignments were made by standard gCOSY experiments. Melting point of sample was taken via melting point apparatus without correcting the thermometer. High resolution mass spectrometric analysis was performed on a VG Micromass ZAB 2F HS (FAB) or Micromass Quattro II triple quadrupole mass spectrometer (Manchester, UK) equipped with an electrospray ionization source (ESI). For ionic compounds, both the cation (C) and the anion (A) were analyzed; usually, only the ion corresponding to the cation (C) component was reported. The thermogravimetric analysis (TGA) measurements were performed on a TGA Q500 from TA instruments. The running method used was ramped from $25{ }^{\circ} \mathrm{C}$ to $550{ }^{\circ} \mathrm{C}, 20{ }^{\circ} \mathrm{C} / \mathrm{min}$, 
under nitrogen, switching to air and then ramped at $20{ }^{\circ} \mathrm{C} / \mathrm{min}$ to $700{ }^{\circ} \mathrm{C}$. The type of pan used was platinum. The high-pressure liquid chromatography (HPLC) analysis was performed using reversed phase $\mathrm{C}_{18}$ column (Agilent Zorbax Extend-C18) and eluting in a linear gradient fashion from $50 \%$ to $100 \%$ of B in A over 20 min, followed by a linear gradient elution from $100 \%$ to $50 \%$ of $\mathrm{B}$ in A over 10 min, where $\mathrm{A}$ is $\mathrm{H}_{2} \mathrm{O} / 0.05 \%$ TFA $(\mathrm{v} / \mathrm{v})$ and $\mathrm{B}$ is $\mathrm{CH}_{3} \mathrm{CN} / 0.05 \%$ TFA $(\mathrm{v} / \mathrm{v})$, at a flow rate of $0.8 \mathrm{~mL} / \mathrm{min}$. The eluted compounds were detected with UV absorbance at $210 \mathrm{~nm}$.
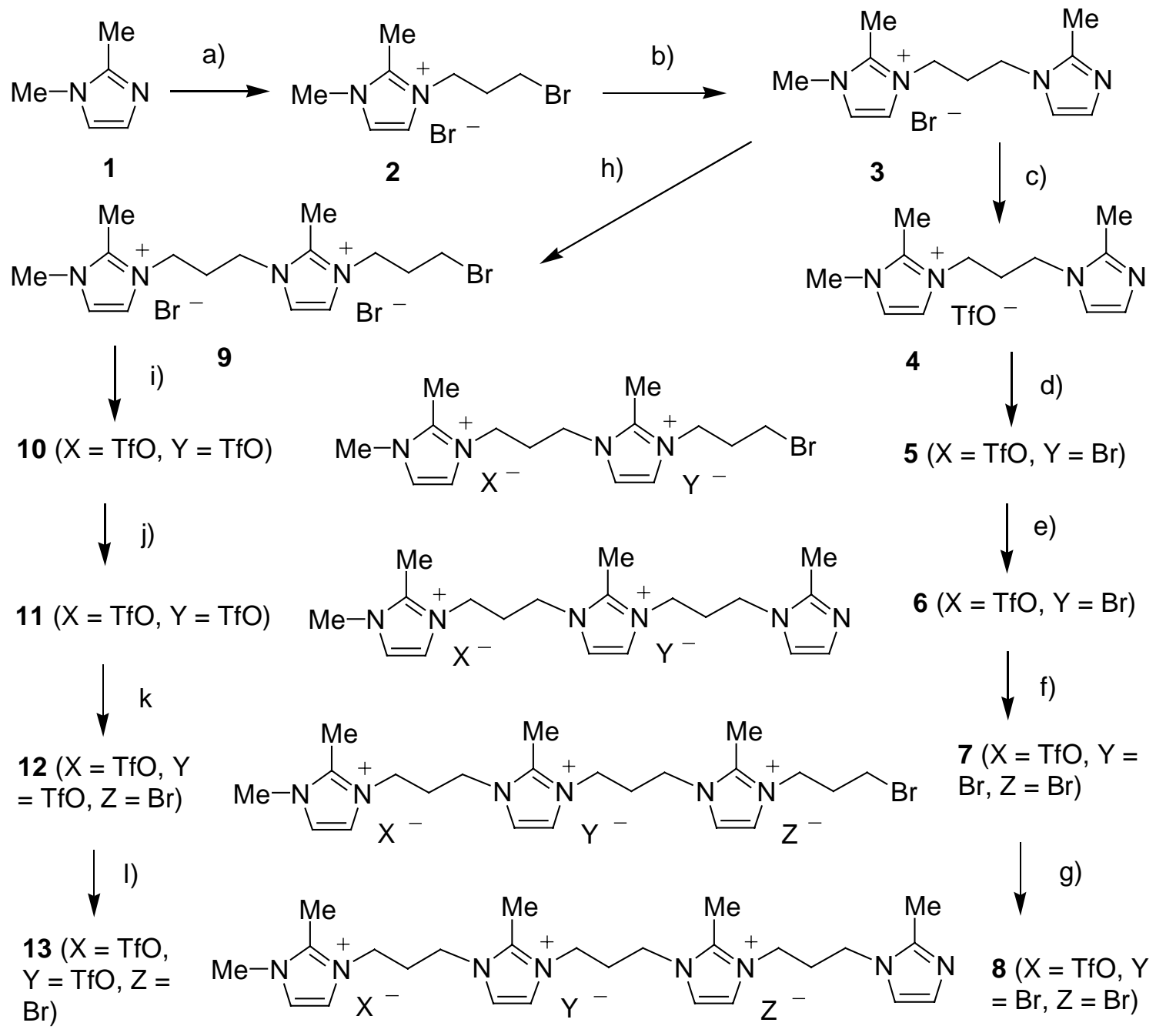
Scheme 1. Synthesis of imidazolium-type ionic oligomers. Reagents and conditions: a) 1,3-dibromopropane (2 equiv.), $\mathrm{CH}_{3} \mathrm{CN}$, reflux, $14 \mathrm{~h}, 80 \%$; b) 2-methylimidazole (2 equiv.), $\mathrm{CH}_{3} \mathrm{CN}$, reflux, 24h, then $\mathrm{K}_{2} \mathrm{CO}_{3}, \mathrm{H}_{2} \mathrm{O}$, rt, 1h, 74\%; c) AgOTf (1 equiv.), $\mathrm{CH}_{3} \mathrm{CN}$, rt, 1h, $100 \%$; d) 1,3-dibromopropane (20 equiv.), $\mathrm{CH}_{3} \mathrm{CN}$, reflux, $17 \mathrm{~h}, 80 \%$; e) 2-methylimidazole (3.6 equiv.), $\mathrm{CH}_{3} \mathrm{CN}$, reflux, 24h, then $\mathrm{K}_{2} \mathrm{CO}_{3}, \mathrm{H}_{2} \mathrm{O}$, rt, $1 \mathrm{~h}, 74 \%$; f) 1,3-dibromopropane (20 equiv.), $\mathrm{CH}_{3} \mathrm{CN}$, reflux, 26h, 84\%; g) 2-methylimidazole (3.4 equiv.), $\mathrm{CH}_{3} \mathrm{CN}$, reflux, 24h, then $\mathrm{K}_{2} \mathrm{CO}_{3}, \mathrm{H}_{2} \mathrm{O}$, rt, 1h, 75\%; h) 1,3-dibromopropane (10 equiv.), $\mathrm{CH}_{3} \mathrm{CN}$, reflux, 25h, 98\%; i) $\mathrm{AgOTf}$ (1 equiv.), $\mathrm{CH}_{3} \mathrm{CN} / \mathrm{CH}_{3} \mathrm{OH}$ (v/v =3:1), rt, 1h, 100\%; j) 2-methylimidazole (3.2 equiv.), $\mathrm{CH}_{3} \mathrm{CN}$, reflux, 24h, then $\mathrm{K}_{2} \mathrm{CO}_{3}, \mathrm{H}_{2} \mathrm{O}$, rt, 30 min, 85\%; k) 1,3-dibromopropane (20 equiv.), $\mathrm{CH}_{3} \mathrm{CN}$, reflux, 28h, 80\%; 1) 2methylimidazole (4 equiv.), $\mathrm{CH}_{3} \mathrm{CN}$, reflux, $24 \mathrm{~h}$, then $\mathrm{K}_{2} \mathrm{CO}_{3}, \mathrm{H}_{2} \mathrm{O}$, rt, 30 min, $70 \%$.

Compound 2: To the solution of 1, 3-dibromopropane (12.5 mL, $122.4 \mathrm{mmol})$ in acetonitrile $(25 \mathrm{~mL})$ was added a solution of 1, 2-dimethylimidazole (5.66 g, $59.0 \mathrm{mmol})$ in acetonitrile $(10 \mathrm{~mL})$ dropwise at $90{ }^{\circ} \mathrm{C}$. After refluxing at $90{ }^{\circ} \mathrm{C}$ for 14 hours, the solvent was removed by rotary evaporation under reduced pressure and the residue was washed with diethyl ether for 4 times, dried in vacuo to give white powder which was added with $40 \mathrm{~mL}$ of dry acetonitrile. The insoluble precipitate was removed through phase separation after centrifugation. The solution phase was collected and solvent was removed by rotary evaporation under vacuum. The product was dried in vacuo and obtained as white solid (14.2 $\mathrm{g}, 80 \%$ yield).

M. P. 96-98 ${ }^{\circ} \mathrm{C} ;{ }^{1} \mathrm{H}$ NMR $\left(400 \mathrm{MHz}, \mathrm{D}_{2} \mathrm{O}\right) \delta 7.30(\mathrm{~d}, 1 \mathrm{H}, \mathrm{J}=2 \mathrm{~Hz}), 7.24(\mathrm{~d}, 1 \mathrm{H}, \mathrm{J}=2$ $\mathrm{Hz}), 4.20(\mathrm{t}, 2 \mathrm{H}, \mathrm{J}=7.2 \mathrm{~Hz}), 3.67(\mathrm{~s}, 3 \mathrm{H}), 3.37(\mathrm{t}, 2 \mathrm{H}, \mathrm{J}=5.6 \mathrm{~Hz}), 2.53(\mathrm{~s}, 3 \mathrm{H}), 2.28(\mathrm{~m}$, 
$2 \mathrm{H}) ;{ }^{13} \mathrm{C}$ NMR $\left(400 \mathrm{MHz}, \mathrm{D}_{2} \mathrm{O}\right) \delta 144.72,122.67,121.00,46.70,35.29,31.98,30.26$, 9.81; HRMS (ESI): calcd for $\mathrm{C}_{8} \mathrm{H}_{14} \mathrm{~N}_{2} \mathrm{Br}\left(\mathrm{C}^{+}\right)$217.0337, found: 217.0334 .

Compound 3: To the flask with compound $2(22.05 \mathrm{~g}, 74.0 \mathrm{mmol})$ and 2methylimidazole (13.53 g, $164.9 \mathrm{mmol})$ was added dry acetonitrile $(200 \mathrm{~mL})$ under the protection of nitrogen. The reaction mixture was refluxed for 24 hours and then cooled to room temperature. The solvent was removed by rotary evaporation under vacuum and the residue was washed with diethyl ether for two times and THF for four times to give white powder. The phase separation during washing process was conducted by centrifugation and decantation. After having been dried in vacuo for two hours, the white powder was added with $150 \mathrm{~mL}$ of water and $\mathrm{K}_{2} \mathrm{CO}_{3}(\mathrm{pH}=11)$ and stirred for half an hour. The water was removed under freeze-dry condition and the residue was added with acetonitrile. After filtering off the insoluble inorganic salt, the filtrate was collected and rotary evaporated to dryness and the residue was then washed with THF and ether to afford the final product as white powder (16.4 g, 74\% yield).

M. P. $159-161{ }^{\circ} \mathrm{C} ;{ }^{1} \mathrm{H}$ NMR $\left(400 \mathrm{MHz}, \mathrm{D}_{2} \mathrm{O}\right) \delta$ 7.12-7.10 (m, 2H), $6.85(\mathrm{~d}, 1 \mathrm{H}, \mathrm{J}=1.2$ Hz), $6.68(\mathrm{~d}, 1 \mathrm{H}, \mathrm{J}=1.2 \mathrm{~Hz}), 3.95(\mathrm{t}, 2 \mathrm{H}, \mathrm{J}=7.2 \mathrm{~Hz}), 3.86(\mathrm{t}, 2 \mathrm{H}, 6.8 \mathrm{~Hz}), 3.55(\mathrm{~s}, 3 \mathrm{H})$, $2.32(\mathrm{~s}, 3 \mathrm{H}), 2.14(\mathrm{~m}, 5 \mathrm{H}) ;{ }^{13} \mathrm{C}$ NMR $\left(400 \mathrm{MHz}, \mathrm{D}_{2} \mathrm{O}\right) \delta 145.99,144.40,126.06,122.60$, 120.51, 120.20, 45.62, 43.08, 35.02, 29.70, 12.09, 9.29; HRMS (ESI): calcd for $\mathrm{C}_{12} \mathrm{H}_{19} \mathrm{~N}_{4}$ $\left(C^{+}\right)$219.1604, found: 219.1604 .

Compound 4: To a solution of compound $\mathbf{3}$ (4.88 g, $16.3 \mathrm{mmol})$ in acetonitrile (60 mL) was added a solution of AgOTf $(4.18 \mathrm{~g}, 16.3 \mathrm{mmol})$ in acetonitrile $(10 \mathrm{~mL})$. The mixture was stirred for 1 hour in the dark and filtered to remove the yellow precipitate. The 
filtrate was rotary evaporated under reduced pressure to give the product as white solid (6.06g, 100\% yield).

M. P. $120-122{ }^{\circ} \mathrm{C} ;{ }^{1} \mathrm{H}$ NMR (400 MHz, $\left.\mathrm{D}_{2} \mathrm{O}\right) \delta 7.13(\mathrm{~m}, 2 \mathrm{H}), 6.87(\mathrm{~d}, 1 \mathrm{H}, \mathrm{J}=1.2 \mathrm{~Hz})$, 6.71(d, 1H, J=1.2 Hz), 3.96 (t, 2H, 7.2 Hz), 3.87 (t, 2H, 7.2 Hz), 3.56(s, 3H), $2.33(\mathrm{~s}, 3 \mathrm{H})$, $2.14(\mathrm{~m}, 5 \mathrm{H}) ;{ }^{13} \mathrm{C} \mathrm{NMR}\left(400 \mathrm{MHz}, \mathrm{D}_{2} \mathrm{O}\right) \delta 145.97,144.42,125.80,122.57,120.45$, 120.15, 45.34, 42.84, 34.66, 29.40, 11.63, 8.78; HRMS (ESI): calcd for $\mathrm{C}_{12} \mathrm{H}_{19} \mathrm{~N}_{4}\left(\mathrm{C}^{+}\right)$ 219.1604, found: 219.1604 .

Compound 5: To the flask with compound 4 (5.51 g, $15.0 \mathrm{mmol})$ was added 1,3dibromopropane $(30 \mathrm{~mL}, 293.7 \mathrm{mmol})$ and dry acetonitrile $(100 \mathrm{~mL})$. The reaction mixture was refluxed for 17 hours under the protection of nitrogen. The mixture was cooled to room temperature and then rotary evaporated under reduced pressure to remove solvent. The residue was washed with diethyl ether for four times and then vacuumed to dryness for 30 minutes to give white solid. After adding dry acetonitrile (100 mL) to the solid, the precipitate was removed by phase separation through centrifugation and decantation. The solution phase was collected and rotary evaporated under reduced pressure to give product $(6.81 \mathrm{~g}, 80 \%)$ as faun solid.

M. P. $76-78{ }^{\circ} \mathrm{C} ;{ }^{1} \mathrm{H}$ NMR (400 MHz, $\left.\mathrm{D}_{2} \mathrm{O}\right) \delta 7.28(\mathrm{~d}, 1 \mathrm{H}, \mathrm{J}=2.4 \mathrm{~Hz}), 7.24(\mathrm{~d}, 1 \mathrm{H}, \mathrm{J}=2.0$ $\mathrm{Hz}), 7.19(\mathrm{~d}, 1 \mathrm{H}, \mathrm{J}=2.0 \mathrm{~Hz}), 7.16(\mathrm{~d}, 1 \mathrm{H}, \mathrm{J}=2.4 \mathrm{~Hz}), 4.13(\mathrm{t}, 2 \mathrm{H}, \mathrm{J}=6.8 \mathrm{~Hz}), 4.06(\mathrm{t}$, $2 \mathrm{H}, \mathrm{J}=7.6 \mathrm{~Hz}), 3.58(\mathrm{~s}, 3 \mathrm{H}), 3.29(\mathrm{t}, 2 \mathrm{H}, \mathrm{J}=5.6 \mathrm{~Hz}), 2.48(\mathrm{~s}, 3 \mathrm{H}), 2.41(\mathrm{~s}, 3 \mathrm{H}), 2.20(\mathrm{~m}$, $4 \mathrm{H}) ;{ }^{13} \mathrm{C}$ NMR $\left(400 \mathrm{MHz}, \mathrm{D}_{2} \mathrm{O}\right) \delta 144.58,144.42,122.67,121.65,121.09,120.43,46.66$, 45.16, 45.10, 34.95, 31.56, 29.70, 29.20, 9.44, 9.21; HRMS (ESI): calcd for $\mathrm{C}_{16} \mathrm{H}_{25} \mathrm{~N}_{4} \mathrm{BrO}_{3} \mathrm{~F}_{3} \mathrm{~S}\left(\mathrm{M}^{+}-\mathrm{Br}\right) 489.0780$, found: 489.0777 . 
Compound 6: To the flask with compound $5(4.89 \mathrm{~g}, 8.58 \mathrm{mmol})$ and 2-methylimidazole (2.56 g, $31.2 \mathrm{mmol})$ was added dry acetonitrile $(45 \mathrm{~mL})$. The reaction mixture was refluxed at $90{ }^{\circ} \mathrm{C}$ for 24 hours and then cooled to room temperature. This was followed by rotary evaporation under reduced pressure to remove solvent. The residue was washed with THF and diethyl ether and then vacuumed to dryness for $30 \mathrm{~min}$ to give a white power. To the powder was added $60 \mathrm{~mL}$ of water and $\mathrm{K}_{2} \mathrm{CO}_{3}(\mathrm{pH}=11)$ and stirred for half an hour. The water was removed under freeze-dry condition and the residue was added with acetonitrile. After filtering off the insoluble salt, the filtrate was collected and rotary evaporated to dryness and the residue was further washed with THF and diethyl ether to afford the final product as white foam $(3.59 \mathrm{~g}, 74 \%$ yield $)$.

M. P. $121-123{ }^{\circ} \mathrm{C} ;{ }^{1} \mathrm{H}$ NMR $\left(400 \mathrm{MHz}, \mathrm{D}_{2} \mathrm{O}\right) \delta 7.27(\mathrm{~m}, 4 \mathrm{H}), 6.92(\mathrm{~s}, 1 \mathrm{H}), 6.74(\mathrm{~s}, 1 \mathrm{H})$, 4.14-4.02 (m, 6H), $3.95(\mathrm{t}, 2 \mathrm{H}, \mathrm{J}=6.4 \mathrm{~Hz}), 3.65(\mathrm{~s}, 3 \mathrm{H}), 2.48(\mathrm{~s}, 3 \mathrm{H}), 2.43(\mathrm{~s}, 3 \mathrm{H})$, $2.21(\mathrm{~m}, 7 \mathrm{H}) ;{ }^{13} \mathrm{C}$ NMR $\left(400 \mathrm{MHz}, \mathrm{D}_{2} \mathrm{O}\right) \delta 146.03,144.68,144.22,126.01,122.77$, $121.32,121.23,120.52,120.17,45.84,45.23,45.18,43.18,35.04,29.47,29.27,12.02$, 9.34; HRMS (ESI): calcd for $\mathrm{C}_{20} \mathrm{H}_{30} \mathrm{~N}_{6} \mathrm{O}_{3} \mathrm{~F}_{3} \mathrm{~S}$ ( $\mathrm{M}^{+}-\mathrm{Br}$ ) 491.2049, found: 491.2046 .

Compound 7: To the flask with compound 6 (3.22 g, $5.65 \mathrm{mmol})$ was added 1,3dibromopropane $(11 \mathrm{~mL}, 107.7 \mathrm{mmol})$ and dry acetonitrile $(35 \mathrm{~mL})$. The reaction mixture was refluxed for 26 hours at $90{ }^{\circ} \mathrm{C}$ under the protection of nitrogen, cooled to room temperature and then rotary evaporated under reduced pressure to remove solvent. The residue was washed with THF for three times and diethyl ether for two times and then vacuumed to dryness for $30 \mathrm{~min}$ to give white solid. After adding dry acetonitrile (100 $\mathrm{mL}$ ) to the solid, the precipitate was removed by phase separation through centrifugation 
and decantation. The solution phase was collected and rotary evaporated under reduced pressure to give product as thick oil (3.66 $\mathrm{g}, 84 \%)$.

${ }^{1} \mathrm{H}$ NMR (400 MHz, D $\left.2 \mathrm{O}\right) \delta$ 7.31-7.27 (m, 4H), $7.21(\mathrm{~d}, 1 \mathrm{H}, \mathrm{J}=2 \mathrm{~Hz}), 7.18(\mathrm{~d}, 1 \mathrm{H}, \mathrm{J}=2$ $\mathrm{Hz}), 4.15(\mathrm{t}, 2 \mathrm{H}, \mathrm{J}=6.8 \mathrm{~Hz}), 4.11-4.05(\mathrm{~m}, 8 \mathrm{H}), 3.60(\mathrm{~s}, 3 \mathrm{H}), 3.30(\mathrm{t}, 2 \mathrm{H}, \mathrm{J}=6.4 \mathrm{~Hz})$, $2.50(\mathrm{~s}, 3 \mathrm{H}), 2.46(\mathrm{~s}, 3 \mathrm{H}), 2.42(\mathrm{~s}, 3 \mathrm{H}), 2.21(\mathrm{~m}, 6 \mathrm{H}) ;{ }^{13} \mathrm{C} \mathrm{NMR}\left(400 \mathrm{MHz}, \mathrm{D}_{2} \mathrm{O}\right) \delta$ $144.71,144.56,122.78,121.78,121.30,121.24,120.56,46.58,45.13,45.07,44.99$, 34.84, 31.47, 29.71, 29.06, 29.01, 9.28, 9.20, 9.04; HRMS (ESI) calcd for $\mathrm{C}_{23} \mathrm{H}_{36} \mathrm{~N}_{6} \mathrm{O}_{3} \mathrm{~F}_{3} \mathrm{SBr}\left(\mathrm{M}^{2+}-2 \mathrm{Br}\right) 306.0847$, found: 306.0850 .

Compound 8: To the flask with compound 7 (2.42 g, $3.13 \mathrm{mmol})$ and 2-methylimidazole (0.88 g, $10.7 \mathrm{mmol})$ was added dry acetonitrile $(45 \mathrm{~mL})$. The reaction mixture was refluxed at $90{ }^{\circ} \mathrm{C}$ for 24 hours and then cooled to room temperature. This was followed by rotary evaporation under reduced pressure to remove solvent. The residue was washed with THF and diethyl ether and then vacuumed to dryness for $30 \mathrm{~min}$ to give white powder. To the powder was added $50 \mathrm{~mL}$ of water and $\mathrm{K}_{2} \mathrm{CO}_{3}(\mathrm{pH}=11)$ and stirred for half an hour. The water was removed under freeze-dry condition and the residue was added with acetonitrile. After filtering off the insoluble inorganic salt, the filtrate was collected and rotary evaporated to dryness and residue was then washed with THF and diethyl ether to afford the final product as sticky white foam $(1.81 \mathrm{~g}, 75 \%$ yield $)$.

${ }^{1} \mathrm{H}$ NMR $\left(400 \mathrm{MHz}, \mathrm{D}_{2} \mathrm{O}\right) \delta 7.30(\mathrm{~m}, 2 \mathrm{H}), 7.25-7.17(\mathrm{~m}, 4 \mathrm{H}), 6.88(\mathrm{~s}, 1 \mathrm{H}), 6.70(\mathrm{~s}, 1 \mathrm{H})$, 4.11-4.05 (m, 8H), $4.00(\mathrm{t}, 2 \mathrm{H}, \mathrm{J}=7.2 \mathrm{~Hz}), 3.91(\mathrm{t}, 2 \mathrm{H}, \mathrm{J}=6.8 \mathrm{~Hz}), 3.61(\mathrm{~s}, 3 \mathrm{H}), 2.48(\mathrm{~s}$, 3H), $2.44(\mathrm{~s}, 3 \mathrm{H}), 2.40(\mathrm{~s}, 3 \mathrm{H}), 2.26-2.14(\mathrm{~m}, 9 \mathrm{H}) ;{ }^{13} \mathrm{C} \mathrm{NMR}\left(500 \mathrm{MHz}, \mathrm{CD}_{3} \mathrm{CN}\right) \delta$ $145.17,145.13,144.84,144.55,127.12,122.80,122.56,121.54,120.99,120.01,119.37$ 
45.72, 45.18, 42.66, 35.05, 30.32, 29.42, 29.33, 12.38, 9.70, 9.56, 9.49; HRMS (ESI): calcd for $\mathrm{C}_{27} \mathrm{H}_{41} \mathrm{~N}_{8} \mathrm{O}_{3} \mathrm{~F}_{3} \mathrm{~S}\left(\mathrm{M}^{2+}-2 \mathrm{Br}\right)$ 307.1481; found: 307.1483 .

Compound 9: To the flask with compound 3 (2.75 g, $9.22 \mathrm{mmol})$ was added 1,3dibromopropane $(10 \mathrm{~mL}, 97.9 \mathrm{mmol})$ and dry acetonitrile $(100 \mathrm{~mL})$. The reaction mixture was refluxed for 25 hours under the protection of nitrogen, cooled to room temperature and then rotary evaporated under reduced pressure to remove solvent. The residue was washed with diethyl ether for four times and then vacuumed to dryness to give the product as white powder (4.52 $\mathrm{g}, 98 \%$ yield).

M.P. $=201-203{ }^{\circ} \mathrm{C} ;{ }^{1} \mathrm{H}$ NMR $\left(500 \mathrm{MHz}, \mathrm{D}_{2} \mathrm{O}\right) \delta 7.36(\mathrm{~d}, 1 \mathrm{H}, \mathrm{J}=2 \mathrm{~Hz}), 7.33(\mathrm{~d}, 1 \mathrm{H}, \mathrm{J}=2$ $\mathrm{Hz}), 7.28(\mathrm{~d}, 1 \mathrm{H}, \mathrm{J}=2 \mathrm{~Hz}), 7.24(\mathrm{~d}, 1 \mathrm{H}, \mathrm{J}=2 \mathrm{~Hz}), 4.19(\mathrm{t}, 2 \mathrm{H}, \mathrm{J}=7 \mathrm{~Hz}), 4.13(\mathrm{~m}, 4 \mathrm{H})$, $3.65(\mathrm{~s}, 3 \mathrm{H}), 3.36(\mathrm{t}, 2 \mathrm{H}, \mathrm{J}=6 \mathrm{~Hz}), 2.55(\mathrm{~s}, 3 \mathrm{H}), 2.48(\mathrm{~s}, 3 \mathrm{H}), 2.27(\mathrm{~m}, 4 \mathrm{H}) ;{ }^{13} \mathrm{C} \mathrm{NMR}$ $\left(400 \mathrm{MHz}, \mathrm{D}_{2} \mathrm{O}\right) \delta 144.71,144.55,122.82,121.80,121.29,120.63,46.87,45.40,45.34$, 35.23, 31.76, 30.14, 29.38, 9.90, 9.66; HRMS (ESI): calcd for $\mathrm{C}_{15} \mathrm{H}_{25} \mathrm{~N}_{4} \mathrm{Br}_{2}\left(\mathrm{M}^{+}-\mathrm{Br}\right)$ 419.0446, found: 419.0440 .

Compound 10: To a solution of compound $9(3.19 \mathrm{~g}, 6.38 \mathrm{mmol})$ in a mixed solvent of acetonitrile $(60 \mathrm{~mL})$ and methanol $(18 \mathrm{~mL})$ was added a solution of AgOTf $(3.27 \mathrm{~g}, 12.8$ mmol) in acetonitrile $(20 \mathrm{~mL})$. The mixture was stirred for 1 hour in the dark and filtered to remove the yellow precipitate. The filtrate was rotary evaporated under reduced pressure and dried in vacuo to give the product ( $4.09 \mathrm{~g}, 100 \%$ yield) as white solid.

M. P. $84-86{ }^{\circ} \mathrm{C} ;{ }^{1} \mathrm{H}$ NMR $\left(400 \mathrm{MHz}, \mathrm{D}_{2} \mathrm{O}\right) \delta 7.32(\mathrm{~d}, 1 \mathrm{H}, \mathrm{J}=2.4 \mathrm{~Hz}), 7.28(\mathrm{~d}, 1 \mathrm{H}, \mathrm{J}=2.0$ Hz), $7.22(\mathrm{~d}, 1 \mathrm{H}, \mathrm{J}=2.0 \mathrm{~Hz}), 4.16(\mathrm{t}, 2 \mathrm{H}, \mathrm{J}=6.8 \mathrm{~Hz}), 4.08(\mathrm{~m}, 4 \mathrm{H}), 3.1(\mathrm{~s}, 3 \mathrm{H}), 3.22(\mathrm{~d}$, $2 \mathrm{H}, \mathrm{J}=6 \mathrm{~Hz}), 2.50(\mathrm{~s}, 3 \mathrm{H}), 2.44(\mathrm{~s}, 3 \mathrm{H}), 2.22(\mathrm{~m}, 4 \mathrm{H}) ;{ }^{13} \mathrm{C} \mathrm{NMR}\left(400 \mathrm{MHz}, \mathrm{D}_{2} \mathrm{O}\right) \delta$ $144.69,144.52,122.77,121.74,121.18,120.51,46.54,45.03,44.97,34.78,31.43,29.60$, 
29.02, 9.17, 8.94; HRMS (ESI): calcd for $\mathrm{C}_{16} \mathrm{H}_{25} \mathrm{~N}_{4} \mathrm{BrO}_{3} \mathrm{~F}_{3} \mathrm{~S}$ (M+-TfO) 489.0780, found: 489.0777 .

Compound 11: To the flask with compound $10(3.87 \mathrm{~g}, 6.07 \mathrm{mmol})$ and 2methylimidazole $(1.61 \mathrm{~g}, 19.7 \mathrm{mmol})$ was added dry acetonitrile $(110 \mathrm{~mL})$. The reaction mixture was refluxed at $90{ }^{\circ} \mathrm{C}$ for 24 hours and then cooled to room temperature. This was followed by rotary evaporation under reduced pressure to remove solvent. The residue was washed with THF and diethyl ether and then vacuumed to dryness for $30 \mathrm{~min}$ to give a white power. To the powder was added $50 \mathrm{~mL}$ of water and $\mathrm{K}_{2} \mathrm{CO}_{3}(\mathrm{pH}=11)$ and stirred for half an hour. The water was removed under freeze-dry condition and the residue was added with acetonitrile. After filtering off the insoluble inorganic salt, the filtrate was collected and rotary evaporated to dryness and the residue was further washed with THF and diethyl ether to afford the final product as white solid (3.27 g, 85\% yield). M. P. $107-109{ }^{\circ} \mathrm{C} ;{ }^{1} \mathrm{H}$ NMR $\left(400 \mathrm{MHz}, \mathrm{D}_{2} \mathrm{O}\right) \delta 7.22(\mathrm{~s}, 2 \mathrm{H}), 7.21(\mathrm{~d}, 1 \mathrm{H}, \mathrm{J}=2.4 \mathrm{~Hz})$, $7.18(\mathrm{~d}, 1 \mathrm{H}, \mathrm{J}=2.4 \mathrm{~Hz}), 6.87(\mathrm{~d}, 1 \mathrm{H}, \mathrm{J}=1.6 \mathrm{~Hz}), 6.70(\mathrm{~d}, 1 \mathrm{H}, \mathrm{J}=1.6 \mathrm{~Hz}), 4.08-4.01(\mathrm{~m}$, 4H), $3.99(\mathrm{t}, 2 \mathrm{H}, \mathrm{J}=7.2 \mathrm{~Hz}), 3.90(\mathrm{t}, 2 \mathrm{H}, \mathrm{J}=6.4 \mathrm{~Hz}), 3.59(\mathrm{~s}, 3 \mathrm{H}), 2.42(\mathrm{~s}, 3 \mathrm{H}), 2.37(\mathrm{~s}$, 3H), 2.17 (m, 7H); ${ }^{13} \mathrm{C}$ NMR (400 MHz, $\left.\mathrm{D}_{2} \mathrm{O}\right) \delta 146.00,144.69,144.24,125.82,122.75$, $121.28,121.18,120.46,120.13,45.57,44.97,44.91,42.94,34.75,29.23,29.00,11.64$, 8.90; HRMS (ESI): calcd for $\mathrm{C}_{20} \mathrm{H}_{30} \mathrm{~N}_{6} \mathrm{O}_{3} \mathrm{~F}_{3} \mathrm{~S}$ ( $\mathrm{M}^{+}$-TfO) 491.2049, found: 491.2046 .

Compound 12: To the flask with compound 11 (2.07 g, 3.24 mmol) was added 1,3dibromopropane $(7.0 \mathrm{~mL}, 68.5 \mathrm{mmol})$ and dry acetonitrile $(45 \mathrm{~mL})$. The reaction mixture was refluxed for 28 hours at $90{ }^{\circ} \mathrm{C}$ under the protection of nitrogen, cooled to room temperature, and then rotary evaporated under reduced pressure to remove solvent. The residue was washed with THF for three times and diethyl ether for two times and then 
vacuumed to dryness for 30 min to give white solid. After adding dry acetonitrile (80 $\mathrm{mL}$ ) to the solid, the precipitate was removed by phase separation through centrifugation and decantation. The solution phase was collected and rotary evaporated under reduced pressure to give product as white powder $(2.19 \mathrm{~g}, 80 \%$ yield $)$.

M. P. $105-107{ }^{\circ} \mathrm{C} ;{ }^{1} \mathrm{H}$ NMR $\left(400 \mathrm{MHz}, \mathrm{D}_{2} \mathrm{O}\right) \delta 7.31(\mathrm{~d}, 1 \mathrm{H}, \mathrm{J}=2.4 \mathrm{~Hz}), 7.28(\mathrm{~m}, 2 \mathrm{H})$, $7.27(\mathrm{~d}, 1 \mathrm{H}, \mathrm{J}=2.4 \mathrm{~Hz}), 7.21(\mathrm{~d}, 1 \mathrm{H}, \mathrm{J}=2.0 \mathrm{~Hz}), 7.18(\mathrm{~d}, 1 \mathrm{H}, \mathrm{J}=2.0 \mathrm{~Hz}), 4.15(\mathrm{t}, 2 \mathrm{H}, \mathrm{J}$ $=6.8 \mathrm{~Hz}), 4.11-4.06(\mathrm{~m}, 8 \mathrm{H}), 3.60(\mathrm{~s}, 3 \mathrm{H}), 3.31(\mathrm{t}, 2 \mathrm{H}, \mathrm{J}=6.4 \mathrm{~Hz}), 2.50(\mathrm{~s}, 3 \mathrm{H}), 2.47(\mathrm{~s}$, 3H), $2.43(\mathrm{~s}, 3 \mathrm{H}), 2.22(\mathrm{~m}, 6 \mathrm{H}) ;{ }^{13} \mathrm{C} \mathrm{NMR}\left(400 \mathrm{MHz}, \mathrm{D}_{2} \mathrm{O}\right) \delta 144.64,144.48,122.73$, $121.74,121.33,121.16,120.49,46.73,45.26,45.19,45.12,34.97,31.61,29.78,29.23$, 29.17, 9.46, 9.35, 9.21; HRMS (ESI): calcd for $\mathrm{C}_{24} \mathrm{H}_{36} \mathrm{~N}_{6} \mathrm{O}_{6} \mathrm{~F}_{6} \mathrm{~S}_{2} \mathrm{Br}\left(\mathrm{M}^{+}-\mathrm{Br}\right)$ 761.1231, found: 761.1219 .

Compound 13: To the flask with compound 12 (2.05 g, $2.43 \mathrm{mmol})$ and 2methylimidazole $(0.80 \mathrm{~g}, 9.85 \mathrm{mmol})$ was added dry acetonitrile $(45 \mathrm{~mL})$. The reaction mixture was refluxed at $90{ }^{\circ} \mathrm{C}$ for 24 hours and then cooled to room temperature. This was followed by rotary evaporation under reduced pressure to remove solvent. The residue was washed with THF and diethyl ether and then vacuumed to dryness for $30 \mathrm{~min}$ to give white powder. To the powder was added $50 \mathrm{~mL}$ of water and $\mathrm{K}_{2} \mathrm{CO}_{3}(\mathrm{pH}=11)$ and stirred for half an hour. The water was removed under freeze-dry condition and the residue was added with acetonitrile. After filtering off the insoluble inorganic salt, the filtrate was collected and rotary evaporated to dryness and the residue was further washed with THF and diethyl ether to give the final product as white solid (1.43 g, 70\% yield).

M. P. $96-98{ }^{\circ} \mathrm{C} ;{ }^{1} \mathrm{H}$ NMR $\left(400 \mathrm{MHz}, \mathrm{D}_{2} \mathrm{O}\right) \delta 7.27(\mathrm{~s}, 2 \mathrm{H}), 7.22(\mathrm{~m}, 2 \mathrm{H}), 7.20(\mathrm{~d}, 1 \mathrm{H}, \mathrm{J}=$ $2.4 \mathrm{~Hz}), 7.19(\mathrm{~d}, 1 \mathrm{H}, \mathrm{J}=2.4 \mathrm{~Hz}), 6.86(\mathrm{~d}, 1 \mathrm{H}, \mathrm{J}=1.2 \mathrm{~Hz}), 6.69(\mathrm{~d}, 1 \mathrm{H}, \mathrm{J}=1.2 \mathrm{~Hz}), 4.07$ 
(m, 8H), $3.98(\mathrm{t}, 2 \mathrm{H}, 7.6 \mathrm{~Hz}), 3.89(\mathrm{t}, 2 \mathrm{H}, \mathrm{J}=6.8 \mathrm{~Hz}), 3.59(\mathrm{~s}, 3 \mathrm{H}), 2.46(\mathrm{~s}, 3 \mathrm{H}), 2.42(\mathrm{~s}$,

3H), 2.37 (s, 3H), $2.19(\mathrm{~m}, 9 \mathrm{H}) ;{ }^{13} \mathrm{C}$ NMR $\left(400 \mathrm{MHz}, \mathrm{D}_{2} \mathrm{O}\right) \delta$ 145.95, 144.58, 144.42, $144.14,126.01,122.67,121.29,121.26,121.12,120.43,120.06,45.72,45.19,45.08$, 45.06, 43.04, 34.91, 29.43, 29.18, 29.13, 11.92, 9.30, 9.15; HRMS (ESI): calcd for $\mathrm{C}_{28} \mathrm{H}_{41} \mathrm{~N}_{8} \mathrm{O}_{6} \mathrm{~F}_{6} \mathrm{~S}_{2}\left(\mathrm{M}^{+}-\mathrm{Br}\right)$ 763.2488, found: 763.2489 .

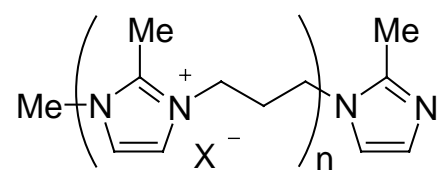

1, $\mathrm{n}=0$

3, $\mathrm{n}=1, \mathrm{X}=\mathrm{Br}$

$11, n=2, X=T f O, T f O$

8, $\mathrm{n}=3, \mathrm{X}=\mathrm{TfO}, \mathrm{Br}, \mathrm{Br}$

13, $\mathrm{n}=3, \mathrm{X}=\mathrm{TfO}, \mathrm{TfO}, \mathrm{Br}$ a) $\mathrm{Br} \widehat{\Upsilon} / \mathrm{m}_{\mathrm{OH}}$

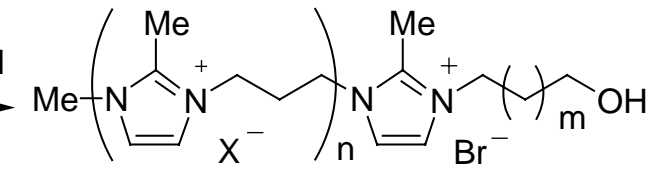

14, $\mathrm{n}=0, \mathrm{~m}=1$

$15, \mathrm{n}=1, \mathrm{~m}=1, \mathrm{X}=\mathrm{Br}$

16, $\mathrm{n}=1, \mathrm{~m}=4, \mathrm{X}=\mathrm{Br}$

$17, \mathrm{n}=2, \mathrm{~m}=1, \mathrm{X}=\mathrm{TfO}, \mathrm{TfO}$

$18, \mathrm{n}=3, \mathrm{~m}=1, \mathrm{X}=\mathrm{TfO}, \mathrm{Br}, \mathrm{Br}$

$19, \mathrm{n}=3, \mathrm{~m}=1, \mathrm{X}=\mathrm{TfO}, \mathrm{TfO}, \mathrm{Br}$

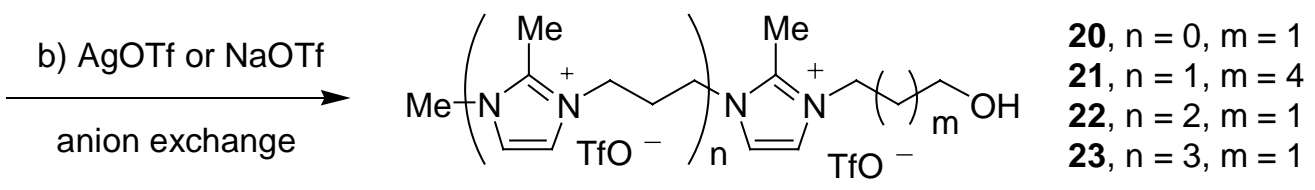

Scheme 2. Synthesis of imidazolium-type ionic oligomers for peptide synthesis supports.

Reagents and conditions: a) bromoalcohol (1.5 equiv.), $\mathrm{CH}_{3} \mathrm{CN}$, reflux, 24h; b) $\mathrm{AgOTf}$ ( 1 equiv.), $\mathrm{CH}_{3} \mathrm{CN}, \mathrm{CH}_{3} \mathrm{OH}$, rt, $1 \mathrm{~h}$, or $\mathrm{NaOTf}$ (1.2 equiv.), $\mathrm{CH}_{3} \mathrm{CN}$, rt, 1-2 days.

General procedures to anchor linkers onto imidazolium salts: To the flask with the imidazolium salt ( 1 equiv.) was added bromoalcohol (1.5 equiv.) and dry acetonitrile (15 $\mathrm{ml} / \mathrm{g}$ of imidazolium salt). The reaction mixture was refluxed at $80-90{ }^{\circ} \mathrm{C}$ for 24 hours under the protection of nitrogen, and then cooled to room temperature. The solvent was removed by rotary evaporation under reduced pressure. The residue was washed with diethyl ether for four times and then vacuumed to dryness to give the product. 
Compound 16: white powder. $98 \%$ yield. M. P. $116-118{ }^{\circ} \mathrm{C} .{ }^{1} \mathrm{H}$ NMR $\left(500 \mathrm{MHz}, \mathrm{D}_{2} \mathrm{O}\right) \delta$ $7.29(\mathrm{~d}, 1 \mathrm{H}, \mathrm{J}=2 \mathrm{~Hz}), 7.28(\mathrm{~d}, 1 \mathrm{H}, \mathrm{J}=2 \mathrm{~Hz}), 7.25(\mathrm{~d}, 1 \mathrm{H}, \mathrm{J}=2.5 \mathrm{~Hz}), 7.22(\mathrm{~d}, 1 \mathrm{H}, \mathrm{J}=$ $2.5 \mathrm{~Hz}), 4.11(\mathrm{~m}, 4 \mathrm{H}), 3.98(\mathrm{t}, 2 \mathrm{H}, \mathrm{J}=7.5 \mathrm{~Hz}), 3.63(\mathrm{~s}, 3 \mathrm{H}), 3.44(\mathrm{t}, 2 \mathrm{H}, \mathrm{J}=6.5 \mathrm{~Hz}), 2.48$ (s, 3H), 2.46(s, 3H), $2.24(\mathrm{~m}, 2 \mathrm{H}), 1.69(\mathrm{~m}, 2 \mathrm{H}), 1.39(\mathrm{~m}, 2 \mathrm{H}), 1.21(\mathrm{~m}, 4 \mathrm{H}) ;{ }^{13} \mathrm{C}$ NMR $\left(500 \mathrm{MHz}, \mathrm{D}_{2} \mathrm{O}\right) \delta 144.74,144.12,122.80,121.70,120.89,120.56,61.75,48.39,45.08$, 45.03, 34.89, 31.18, 29.08, 28.93, 25.42, 24.71, 9.19, 9.12; HRMS (ESI) calcd for $\mathrm{C}_{18} \mathrm{H}_{32} \mathrm{~N}_{4} \mathrm{OBr}\left(\mathrm{M}^{+}-\mathrm{Br}\right)$ 399.1754, found: 399.1754 .

Compound 17: white solid. 87\% yield. m.p.: 90-93 ${ }^{\circ} \mathrm{C} .{ }^{1} \mathrm{H}$ NMR $\left(400 \mathrm{MHz}, \mathrm{D}_{2} \mathrm{O}\right) \delta 7.30$ $(\mathrm{m}, 2 \mathrm{H}), 7.28(\mathrm{~d}, 1 \mathrm{H}, \mathrm{J}=2 \mathrm{~Hz}), 7.27(\mathrm{~d}, 1 \mathrm{H}, \mathrm{J}=2 \mathrm{~Hz}), 7.22(\mathrm{~d}, 1 \mathrm{H}, \mathrm{J}=2.5 \mathrm{~Hz}), 7.18(\mathrm{~d}$, 1H, J = 2.5 Hz), $4.07(\mathrm{~m}, 10 \mathrm{H}), 3.60(\mathrm{~s}, 3 \mathrm{H}), 3.46(\mathrm{t}, 2 \mathrm{H}, \mathrm{J}=6 \mathrm{~Hz}), 2.47(\mathrm{~s}, 6 \mathrm{H}), 2.43(\mathrm{~s}$, 3H), $2.22(\mathrm{~m}, 4 \mathrm{H}), 1.88(\mathrm{~m}, 2 \mathrm{H}) ;{ }^{13} \mathrm{C}$ NMR $\left(400 \mathrm{MHz}, \mathrm{D}_{2} \mathrm{O}\right) \delta$ 144.74, 144.58, 144.40, $122.80,121.74,121.42,121.08,120.59,58.09,45.37,45.18,45.04,34.90,31.26,29.09$, 29.05, 9.32, 9.20, 9.14; HRMS (ESI) calcd for $\mathrm{C}_{24} \mathrm{H}_{37} \mathrm{~N}_{6} \mathrm{O}_{7} \mathrm{~F}_{6} \mathrm{~S}_{2}\left(\mathrm{M}^{+}-\mathrm{Br}\right)$ 699.2063, found: 699.2067 .

Compound 18: white solid. $98 \%$ yield. m.p.: $120-122{ }^{\circ} \mathrm{C} .{ }^{1} \mathrm{H}$ NMR $\left(500 \mathrm{MHz}, \mathrm{D}_{2} \mathrm{O}\right) \delta$ $7.35(\mathrm{~d}, 4 \mathrm{H}), 7.32(\mathrm{~s}, 2 \mathrm{H}), 7.27(\mathrm{~d}, 1 \mathrm{H}, \mathrm{J}=1.5 \mathrm{~Hz}), 7.24(\mathrm{~d}, 1 \mathrm{H}, \mathrm{J}=1.5 \mathrm{~Hz}), 4.15(\mathrm{~m}$, 14H), $3.66(\mathrm{~s}, 3 \mathrm{H}), 3.51(\mathrm{t}, 2 \mathrm{H}, \mathrm{J}=5.5 \mathrm{~Hz}), 2.53(\mathrm{~s}, 9 \mathrm{H}), 2.49(\mathrm{~s}, 3 \mathrm{H}), 2.72(\mathrm{~m}, 6 \mathrm{H}), 1.94$ (m, 2H); ${ }^{13} \mathrm{C}$ NMR $\left(500 \mathrm{MHz}, \mathrm{D}_{2} \mathrm{O}\right) \delta 144.75,144.60,144.41,122.81,121.75,121.43$, $121.08,120.59,58.12,45.39,45.17,45.03,34.89,31.24,29.02,9.25,9.13$; HRMS (ESI) calcd for $\mathrm{C}_{30} \mathrm{H}_{48} \mathrm{~N}_{8} \mathrm{O}_{4} \mathrm{~F}_{3} \mathrm{~S}\left(\mathrm{M}^{3+}-3 \mathrm{Br}\right)$ 224.4485, found: 224.4488 .

Compound 19: white solid, $96 \%$ yield. M. P. $115-117{ }^{\circ} \mathrm{C} .1 \mathrm{H}$ NMR $\left(500 \mathrm{MHz}, \mathrm{D}_{2} \mathrm{O}\right) \delta$ 7.32-7.28 (m, 6H), $7.23(\mathrm{~s}, 1 \mathrm{H}), 7.20(\mathrm{~s}, 1 \mathrm{H}), 4.10(\mathrm{~m}, 14 \mathrm{H}), 3.62(\mathrm{~s}, 3 \mathrm{H}), 3.47(\mathrm{t}, 2 \mathrm{H}, \mathrm{J}=$ $5.5 \mathrm{~Hz}), 2.49(\mathrm{~m}, 9 \mathrm{H}), 2.44(\mathrm{~s}, 3 \mathrm{H}), 2.24(\mathrm{~m}, 6 \mathrm{H}), 1.91(\mathrm{~m}, 2 \mathrm{H}) ;{ }^{13} \mathrm{C} \mathrm{NMR}(400 \mathrm{MHz}$, 
$\left.\mathrm{D}_{2} \mathrm{O}\right) \delta 144.60,144.46,144.26,122.70,121.65,121.31,120.95,120.47,58.14,45.46$, 45.24, 45.10, 34.98, 34.91, 31.35, 29.18, 9.38, 9.30; HRMS (ESI) calcd for $\mathrm{C}_{31} \mathrm{H}_{48} \mathrm{~N}_{8} \mathrm{O}_{7} \mathrm{~F}_{6} \mathrm{~S}_{2}\left(\mathrm{M}^{2+}-2 \mathrm{Br}\right) 411.1490$, found: 411.1490 .

General procedures to synthesize compounds 20-23: To the solution of starting material in a mixed solvent of acetonitrile and methanol was added a solution of AgOTf (1 equiv. to bromide) in acetonitrile. The mixture was stirred for 1 hour in the dark and filtered to remove yellow precipitate. The filtrate was rotary evaporated under reduced pressure and the residue was washed with diethyl ether to give the product.

Compound 21: clear thick oil. $100 \%$ yield. ${ }^{1} \mathrm{H}$ NMR $\left(500 \mathrm{MHz}, \mathrm{D}_{2} \mathrm{O}\right) \delta 7.28(\mathrm{~d}, 1 \mathrm{H}, \mathrm{J}=$ $2 \mathrm{~Hz}), 7.25(\mathrm{~d}, 1 \mathrm{H}, \mathrm{J}=2 \mathrm{~Hz}), 7.23(\mathrm{~d}, 1 \mathrm{H}, \mathrm{J}=2.5 \mathrm{~Hz}), 7.21(\mathrm{~d}, 1 \mathrm{H}, \mathrm{J}=2.5 \mathrm{~Hz}), 4.09(\mathrm{~m}$, 4H), $3.97(\mathrm{t}, 2 \mathrm{H}, \mathrm{J}=7 \mathrm{~Hz}), 3.62(\mathrm{~s}, 3 \mathrm{H}), 3.45(\mathrm{t}, 2 \mathrm{H}, \mathrm{J}=6.5 \mathrm{~Hz}), 2.46(\mathrm{~s}, 3 \mathrm{H}), 2.44(\mathrm{~s}$, 3H), $2.24(\mathrm{~m}, 2 \mathrm{H}), 1.71(\mathrm{~m}, 2 \mathrm{H}), 1.42(\mathrm{~m}, 2 \mathrm{H}), 1.21(\mathrm{~m}, 4 \mathrm{H}) ;{ }^{13} \mathrm{C}$ NMR $(500 \mathrm{MHz}$, $\left.\mathrm{CD}_{3} \mathrm{CN}\right) \delta 145.19,144.57,122.81,121.69,121.43,121.12,61.42,48.43,45.22,45.15$, 35.20, 32.45, 29.67, 29.36, 25.86, 25.27, 9.78; HRMS (ESI) calcd for $\mathrm{C}_{19} \mathrm{H}_{34} \mathrm{~N}_{4} \mathrm{O}_{4} \mathrm{SF}_{3}$ (M+TfO) 469.2090, found: 469.2097.

Compound 22: clear thick oil. ${ }^{1} \mathrm{H}$ NMR $\left(400 \mathrm{MHz}, \mathrm{D}_{2} \mathrm{O}\right) \delta 7.27(\mathrm{~m}, 2 \mathrm{H}), 7.26(\mathrm{~d}, 1 \mathrm{H}, \mathrm{J}$ $=2.4 \mathrm{~Hz}), 7.24(\mathrm{~d}, 1 \mathrm{H}, 2.4 \mathrm{~Hz}), 7.20(\mathrm{~d}, 1 \mathrm{H}, \mathrm{J}=2.4 \mathrm{~Hz}), 7.17(\mathrm{~d}, 1 \mathrm{H}, \mathrm{J}=2.4 \mathrm{~Hz}), 4.06$ (m, 10H), $3.59(\mathrm{~s}, 3 \mathrm{H}), 3.44(\mathrm{t}, 2 \mathrm{H}, \mathrm{J}=6 \mathrm{~Hz}), 2.45(\mathrm{~d}, 6 \mathrm{H}), 2.41(\mathrm{~s}, 3 \mathrm{H}), 2.20(\mathrm{~m}, 4 \mathrm{H})$, $1.86(\mathrm{~m}, 2 \mathrm{H}) ;{ }^{13} \mathrm{C}$ NMR $\left(500 \mathrm{MHz}, \mathrm{D}_{2} \mathrm{O}\right) \delta 144.74,144.57,144.40,122.79,121.74$, $121.38,121.06,121.02,120.54,58.08,45.37,45.11,44.97,34.81,31.20,29.03,28.99$, 9.07, 9.02, 8.94; HRMS (ESI) calcd for $\mathrm{C}_{24} \mathrm{H}_{37} \mathrm{~N}_{6} \mathrm{O}_{7} \mathrm{~F}_{6} \mathrm{~S}_{2}$ (M $\mathrm{M}^{+}$-TfO) 699.2063, found: 699.2065 . 
Compound 23: (derived from 18 or 19), white powder. $100 \%$ yield. M. P. $141-143{ }^{\circ} \mathrm{C}$; ${ }^{1} \mathrm{H}$ NMR $\left(400 \mathrm{MHz}, \mathrm{D}_{2} \mathrm{O}\right) \delta$ 7.29-7.25 (m, 6H), $7.21(\mathrm{~d}, 1 \mathrm{H}, \mathrm{J}=2.0 \mathrm{~Hz}), 7.18(\mathrm{~d}, 1 \mathrm{H}, \mathrm{J}=$ $2.0 \mathrm{~Hz}), 4.09(\mathrm{~m}, 14 \mathrm{H}), 3.61(\mathrm{~s}, 3 \mathrm{H}), 3.46(\mathrm{t}, 2 \mathrm{H}, \mathrm{J}=5.6 \mathrm{~Hz}), 2.47(\mathrm{~s}, 9 \mathrm{H}), 2.43(\mathrm{~s}, 3 \mathrm{H})$, $2.23(\mathrm{~m}, 6 \mathrm{H}), 1.92(\mathrm{~m}, 2 \mathrm{H}) ;{ }^{13} \mathrm{C}$ NMR $\left(500 \mathrm{MHz}, \mathrm{D}_{2} \mathrm{O}\right) \delta 144.73,144.57,122.79,121.74$ $121.39,121.05,121.02,120.53,58.07,45.36,45.08,44.96,34.79,31.20,28.98,9.06$, 9.01, 8.93; HRMS (ESI) calcd for $\mathrm{C}_{31} \mathrm{H}_{48} \mathrm{~N}_{8} \mathrm{O}_{7} \mathrm{~F}_{6} \mathrm{~S}_{2}$ ( $\mathrm{M}^{2+}-2 \mathrm{TfO}$ ) 411.1490, found: 411.1488 . 
(a) Amino acid coupling

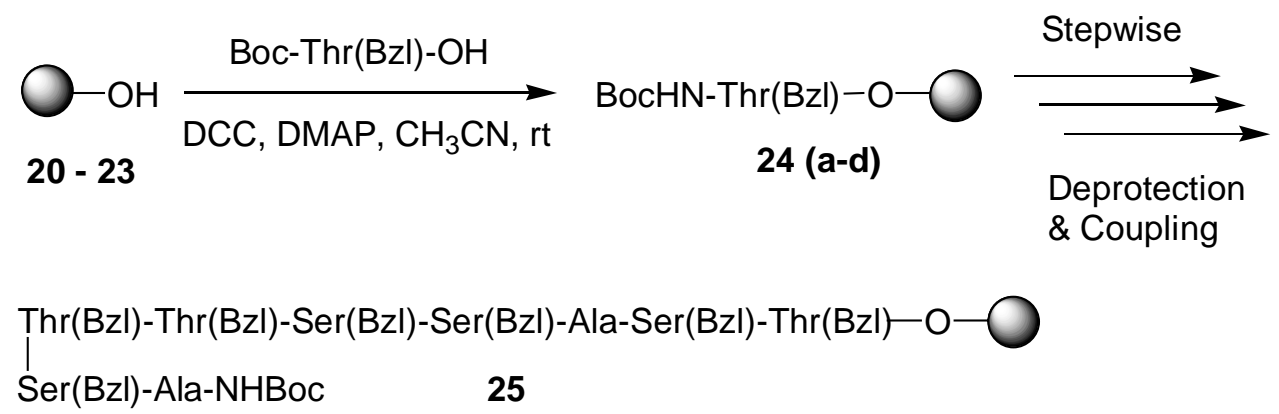

(b) [6+6] Peptide block coupling

BocHN-Thr(Bzl)-Ser(Bzl)-Ser(Bzl)-Ala-Ser(Bzl)-Thr(Bzl)-O-O

26

1) TFA, $\mathrm{CH}_{2} \mathrm{Cl}_{2}$, rt

2) BocHN-Thr(Bzl)-Ser(Bzl)-Ser(Bzl)-Ala-Ser(Bzl)-Thr(Bzl)-OH

(Peptide block coupling) $\quad 27$

$\operatorname{Th}($ Bzl $)-\operatorname{Ser}(B z \mathrm{l})-\operatorname{Ser}(\mathrm{Bz} \mathrm{l})-\mathrm{Ala}-\operatorname{Ser}(\mathrm{Bz} \mathrm{l})-\operatorname{Thr}(\mathrm{Bz} \mathrm{l})-\mathrm{O}-\mathrm{O}$
$\operatorname{Thr}(\mathrm{Bz} \mathrm{l})-\operatorname{Ser}(\mathrm{Bz} \mathrm{l})-\mathrm{Ala}-\operatorname{Ser}(\mathrm{Bz} \mathrm{l})-\operatorname{Ser}(\mathrm{Bz} \mathrm{l})-\operatorname{Thr}(\mathrm{Bz} \mathrm{l})-\mathrm{NHBoc}$

28

(c) [9+6] Peptide block coupling

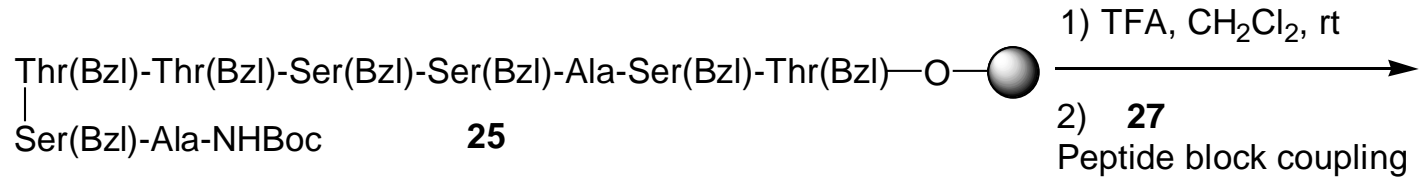

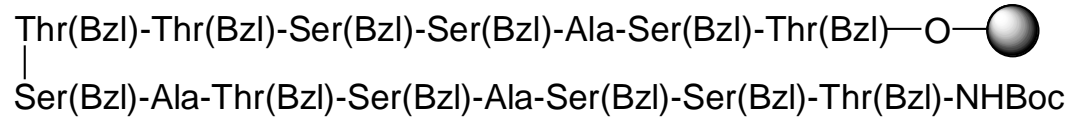

29

Scheme 3. Imidazolium salts-supported amino acid assembling and peptide block couplings.

General procedures to couple amino acid and imidazolium monomer support: To the flask with compound 20 (1.24 g, $4.07 \mathrm{mmol})$ and Boc-Thr(Bzl)-OH (2.28 g, 7.38 mmol ) and DMAP (0.10 g, $0.82 \mathrm{mmol})$ was added dry acetonitrile $(16 \mathrm{~mL})$ and then 1.0 M solution of DCC (9.0 mL, $8.99 \mathrm{mmol})$ in $\mathrm{CH}_{2} \mathrm{Cl}_{2}$. The reaction mixture was stirred for 
24 hours. The white precipitate generated in the reaction was filtered off and the filtrate was collected and subjected to rotary evaporation under reduced pressure. The residue was washed with diethyl ether for four times and dried in vacuo to give the product $\mathbf{2 4 a}$ as clear thick oil ( $2.23 \mathrm{~g}, 92 \%$ yield).

${ }^{1} \mathrm{H}$ NMR $\left(300 \mathrm{MHz}, \mathrm{CDCl}_{3}\right) \delta 7.25(\mathrm{~m}, 7 \mathrm{H}), 5.30(\mathrm{~d}, 1 \mathrm{H}, \mathrm{J}=8.7 \mathrm{~Hz}), 4.61(\mathrm{~d}, 1 \mathrm{H}, 11.7$ Hz), $4.367(\mathrm{~d}, 1 \mathrm{H}, 11.7 \mathrm{~Hz}), 4.21-4.03(\mathrm{~m}, 6 \mathrm{H}), 3.79(\mathrm{~s}, 3 \mathrm{H}), 2.54(\mathrm{~s}, 3 \mathrm{H}), 2.10(\mathrm{~m}, 2 \mathrm{H})$, 1.45 (s, 9H), 1.30 (d, 3H, $6.3 \mathrm{~Hz}) ;{ }^{13} \mathrm{C}$ NMR (400 MHz, $\left.\mathrm{CDCl}_{3}\right) \delta$ 171.15, 156.31, $144.32,137.89,128.63,128.09,127.96,122.80,121.30,80.43,74.35,70.97,61.54$, 58.78, 45.51, 35.77, 28.84, 28.73, 16.58, 10.06; HRMS (ESI) calcd for $\mathrm{C}_{24} \mathrm{H}_{36} \mathrm{~N}_{3} \mathrm{O}_{5}\left(\mathrm{C}^{+}\right)$ 446.2649, found: 446.2651 .

General procedures to couple amino acid and imidazolium dimer (21) and oligomers (22, 23): To the flask charged with imidazolium dimer 21 or oligomer (22 or 23) (1 equiv.), amino acid (2 equiv.) and 4-dimethylaminopyridine (DMAP) (0.2 equiv.) was added dry acetonitrile (15ml/g of substrate) and $1.0 \mathrm{M}$ solution of DCC (2 equiv.) in dichloromethane. The mixture was stirred for 16 hours and the white precipitate, dicyclohexylurea, generated in the reaction was filtered off. The filtrate was collected and then subjected to rotary evaporation under reduced pressure to give syrup to which was added ether. The product precipitated and phase separation was accomplished by centrifugation and decantation. The precipitate was further washed with mixed solvents of diethyl ether and ethyl acetate $(\mathrm{V} / \mathrm{V}=1: 1)$ for several times and diethyl ether once,

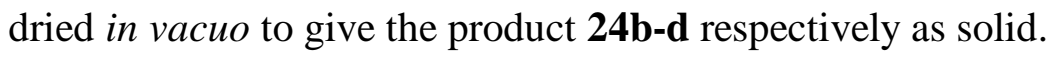

Compound 24b (derived from imidazolium dimer 21): white solid. 83\% yield. m.p.: 44-46 ${ }^{\circ} \mathrm{C} . \quad{ }^{1} \mathrm{H}$ NMR $\left(400 \mathrm{MHz}, \mathrm{CD}_{3} \mathrm{CN}\right) \delta$ 7.39-7.28 (m, 9H), $5.50(\mathrm{~d}, 1 \mathrm{H}, \mathrm{J}=9.2 \mathrm{~Hz})$, 
$4.61(\mathrm{~d}, 1 \mathrm{H}, \mathrm{J}=11.6 \mathrm{~Hz}), 4.39(\mathrm{~d}, 1 \mathrm{H}, \mathrm{J}=11.6 \mathrm{~Hz}), 4.23-3.99(\mathrm{~m}, 10 \mathrm{H}), 3.74(\mathrm{~s}, 3 \mathrm{H})$, $2.56(\mathrm{~d}, 6 \mathrm{H}), 2.87(\mathrm{~m}, 2 \mathrm{H}), 1.76(\mathrm{~m}, 2 \mathrm{H}), 1.62(\mathrm{~m}, 2 \mathrm{H}), 1.48(\mathrm{~s}, 9 \mathrm{H}), 1.36(\mathrm{~m}, 4 \mathrm{H}), 1.26$ $(\mathrm{d}, 3 \mathrm{H}, \mathrm{J}=6.4 \mathrm{~Hz}) ;{ }^{13} \mathrm{C} \mathrm{NMR}\left(400 \mathrm{MHz}, \mathrm{CD}_{3} \mathrm{CN}\right) \delta 171.15,156.15,145.04,144.42$, $138.72,128.46,127.78,127.73,122.92,122.82,121.63,121.23,120.91,79.37,74.83$, $70.70,65.19,58.78,48.50,45.32,45.23,35.26,29.64,29.56,29.40,28.48,27.98,25.83$, 25.40, 15.99, 9.73, 9.67; HRMS (ESI) calcd for $\mathrm{C}_{34} \mathrm{H}_{53} \mathrm{O}_{5} \mathrm{~N}_{5}\left(\mathrm{M}^{2+}-2 \mathrm{TfO}\right)$ 305.7017, found: 305.7017 .

Compound 24c (derived from imidazolium trimer 22): white powder. 88\% yield. M. P. 50-52 ${ }^{\circ} \mathrm{C} ;{ }^{1} \mathrm{H}$ NMR (400 MHz, $\left.\mathrm{CD}_{3} \mathrm{CN}\right) \delta 7.40-7.29(\mathrm{~m}, 11 \mathrm{H}), 5.61(\mathrm{~d}, 1 \mathrm{H}, \mathrm{J}=8.8$ $\mathrm{Hz}), 4.63(\mathrm{~d}, 1 \mathrm{H}, \mathrm{J}=11.6 \mathrm{~Hz}), 4.41(\mathrm{~d}, 1 \mathrm{H}, \mathrm{J}=11.6 \mathrm{~Hz}), 4.28(\mathrm{q}, 1 \mathrm{H}, \mathrm{J}=8.8 \mathrm{~Hz}, 2.8 \mathrm{~Hz})$, 4.19-4.05 (m, 13H), $3.73(\mathrm{~s}, 3 \mathrm{H}), 2.62(\mathrm{~s}, 3 \mathrm{H}), 2.56(\mathrm{~s}, 3 \mathrm{H}), 2.54(\mathrm{~s}, 3 \mathrm{H}), 2.30(\mathrm{~m}, 4 \mathrm{H})$, $2.07(\mathrm{~m}, 2 \mathrm{H}), 1.45(\mathrm{~s}, 9 \mathrm{H}), 1.28(\mathrm{~d}, 3 \mathrm{H}, \mathrm{J}=6 \mathrm{~Hz}) ;{ }^{13} \mathrm{C} \mathrm{NMR}\left(400 \mathrm{MHz}, \mathrm{CD}_{3} \mathrm{CN}\right) \delta$ $171.07,156.26,145.10,145.03,144.76,138.67,128.52,127.96,127.84,122.79,121.72$, $121.56,121.38,120.93,79.52,74.62,70.61,61.57,58.79,54.74,45.27,35.20,29.57$, 29.49, 28.51, 27.98, 15.88, 9.74, 9.63, 9.59; HRMS (ESI) calcd for $\mathrm{C}_{39} \mathrm{H}_{58} \mathrm{O}_{8} \mathrm{~N}_{7} \mathrm{~F}_{3} \mathrm{~S}\left(\mathrm{M}^{2+}\right.$ 2TfO) 420.7004, found: 420.6999; calcd for $\mathrm{C}_{38} \mathrm{H}_{58} \mathrm{O}_{5} \mathrm{~N}_{7}$ ( $\left.\mathrm{M}^{3+}-3 \mathrm{TfO}\right) 230.8161$, found: 230.8161 .

Compound 24d (derived from imidazolium tetramer 23): white powder. 83\% yield. m.p.: $92-94{ }^{\circ} \mathrm{C} .{ }^{1} \mathrm{H}$ NMR $\left(500 \mathrm{MHz}, \mathrm{CD}_{3} \mathrm{CN}\right) \delta$ 7.44-7.29 (m, 13H), $5.62(\mathrm{~d}, 1 \mathrm{H}, \mathrm{J}=9$ $\mathrm{Hz}), 4.61(\mathrm{~d}, 1 \mathrm{H}, \mathrm{J}=11.5 \mathrm{~Hz}), 4.40(\mathrm{~d}, 1 \mathrm{H}, \mathrm{J}=11.5 \mathrm{~Hz}), 4.27-4.06(\mathrm{~m}, 20 \mathrm{H}), 3.73(\mathrm{~s}$, 3H), $2.63(\mathrm{~s}, 3 \mathrm{H}), 2.62(\mathrm{~s}, 3 \mathrm{H}), 2.56(\mathrm{~s}, 3 \mathrm{H}), 2.53(\mathrm{~s}, 3 \mathrm{H}), 2.27$ (m, 6H), $2.06(\mathrm{~m}, 2 \mathrm{H})$, $1.44(\mathrm{~s}, 9 \mathrm{H}), 1.25(\mathrm{~d}, 3 \mathrm{H}, \mathrm{J}=6 \mathrm{~Hz}) ;{ }^{13} \mathrm{C} \mathrm{NMR}\left(400 \mathrm{MHz}, \mathrm{CD}_{3} \mathrm{CN}\right) \delta 171.18,156.35$, $145.15,145.09,144.82,138.72,128.54,127.97,127.85,122.82,122.53,121.74,121.59$, 
$121.56,121.39,120.94,119.98,79.46,74.55,70.55,61.43,58.68,45.21,45.18,45.15$, $35.07,35.05,30.16,29.36,29.27,29.24,28.35,27.79,15.66,9.56,9.44,9.39$; HRMS (ESI) calcd for $\mathrm{C}_{46} \mathrm{H}_{69} \mathrm{~N}_{9} \mathrm{O}_{8} \mathrm{~F}_{3} \mathrm{~S}$ ( $\mathrm{M}^{3+}-3 \mathrm{TfO}$ ) 321.4975, found: 321.4975 .

Compound 25 (imidazolium trimer 22 as support): faun powders. 100\% yield. M. P. 214-216 ${ }^{\circ} \mathrm{C}$, dec.; ${ }^{1} \mathrm{H}$ NMR $\left(500 \mathrm{MHz}, \mathrm{CD}_{3} \mathrm{CN}\right) \delta 7.73$ (s, $\left.1 \mathrm{H}\right), 7.59$ (s, $\left.1 \mathrm{H}\right), 7.45-7.25$ (m, 39H), 7.05 (broad), $5.61(\mathrm{~s}, 1 \mathrm{H}), 4.56-4.36(\mathrm{~m}, 16 \mathrm{H}), 4.30(\mathrm{M}, 5 \mathrm{H}), 4.24-4.04(\mathrm{~m}$, 20H), $3.95(\mathrm{~m}, 1 \mathrm{H}), 3.83(\mathrm{~m}, 1 \mathrm{H}), 3.72(\mathrm{~m}, 9 \mathrm{H}), 3.65(\mathrm{~m}, 2 \mathrm{H}), 3.52(\mathrm{~m}, 2 \mathrm{H}), 2.56(\mathrm{~s}, 3 \mathrm{H})$, $2.53(\mathrm{~s}, 3 \mathrm{H}), 2.51(\mathrm{~s}, 3 \mathrm{H}), 2.25(\mathrm{~m}, 4 \mathrm{H}), 2.06(\mathrm{~m}, 2 \mathrm{H}), 1.37(\mathrm{~s}, 9 \mathrm{H}), 1.34(\mathrm{~d}, 3 \mathrm{H}, \mathrm{J}=7.0$ $\mathrm{Hz}), 1.19(\mathrm{~d}, 3 \mathrm{H}, \mathrm{J}=6.5 \mathrm{~Hz}), 1.16(\mathrm{~d}, 3 \mathrm{H}, \mathrm{J}=7.0 \mathrm{~Hz}), 1.14(\mathrm{~m}, 3 \mathrm{H} . \mathrm{J}=7.5 \mathrm{~Hz}), 1.11(\mathrm{~d}$, $3 \mathrm{H}, \mathrm{J}=6.5 \mathrm{~Hz}$ ); HRMS (ESI) calcd for $\mathrm{C}_{106} \mathrm{H}_{138} \mathrm{O}_{19} \mathrm{~N}_{15}$ ( $\mathrm{M}^{3+}-3 \mathrm{TfO}$ ) 641.6759, found: 641.6759.

Compound 26a (imidazolium monomer 20 as support): faun solid. $100 \%$ yield. ${ }^{1} \mathrm{H}$ NMR (500 MHz, $\left.\mathrm{CDCl}_{3}\right) \delta 7.40(\mathrm{~s}, 2 \mathrm{H}), 7.30-7.19(\mathrm{~m}, 23 \mathrm{H}), 7.01(\mathrm{~s}, 2 \mathrm{H}), 5.39(\mathrm{~d}, 1 \mathrm{H}, \mathrm{J}$ $=4.5 \mathrm{~Hz}), 4.70(\mathrm{~s}, 1 \mathrm{H}), 4.63(\mathrm{~d}, 1 \mathrm{H}, \mathrm{J}=6 \mathrm{~Hz}), 4.50(\mathrm{~m}, 4 \mathrm{H}), 4.40(\mathrm{~m}, 6 \mathrm{H}), 4.24(\mathrm{~m}, 2 \mathrm{H})$, $4.07(\mathrm{~m}, 7 \mathrm{H}), 3.93(\mathrm{~m}, 2 \mathrm{H}), 3.77(\mathrm{~m}, 1 \mathrm{H}), 3.72(\mathrm{~m}, 5 \mathrm{H}), 3.48(\mathrm{~m}, 2 \mathrm{H}), 2.48(\mathrm{~s}, 3 \mathrm{H}), 2.05$ (broad, 2H), 1.40 (m, 12H), 1.17 (m, 6H); ${ }^{13} \mathrm{C}$ NMR $\left(500 \mathrm{MHz}, \mathrm{CDCl}_{3}\right) \delta$ 173.34, 172.23, $171.23,170.87,170.63,170.35,156.46,144.24,138.41,138.06,138.01,137.81,137.21$, $128.82,128.73,128.54,128.52,128.37,128.23,127.97,127.86,127.81,127.57,122.48$, $121.93,81.20,74.82,74.11,73.56,73.19,73.04,71.71,71.16,69.87,68.44,68.04,61.27$, $59.79,57.58,55.68,55.38,53.64,50.68,45.40,35.37,28.44,28.40,17.25,15.56,16.14$, 9.51; HRMS (ESI) calcd for $\mathrm{C}_{68} \mathrm{H}_{87} \mathrm{O}_{14} \mathrm{~N}_{8}\left(\mathrm{C}^{+}\right)$1239.6336, found: 1239.6283; for $\mathrm{C}_{68} \mathrm{H}_{88} \mathrm{O}_{14} \mathrm{~N}_{8}\left(\mathrm{C}^{+}+\mathrm{H}^{+}\right)$620.3204, found: 620.3197 . 
Compound 26b (imidazolium dimer 21 as support): faun powder. 100\% yield. M. P. 173-175 ${ }^{\circ} \mathrm{C} ;{ }^{1} \mathrm{H}$ NMR $\left(400 \mathrm{MHz}, \mathrm{CD}_{3} \mathrm{CN}\right), \delta$ 7.50-7.28 (m, 23H), $7.17(\mathrm{~d}, 1 \mathrm{H}, \mathrm{J}=8.4$ $\mathrm{Hz}), 5.78(\mathrm{~d}, 1 \mathrm{H}, \mathrm{J}=6.4 \mathrm{~Hz}), 4.57-4.26(\mathrm{~m}, 15 \mathrm{H}), 4.10-3.98(\mathrm{~m}, 11 \mathrm{H}), 3.81-3.71(\mathrm{~m}$, 7H), $3.60(\mathrm{~m}, 2 \mathrm{H}), 2.51(\mathrm{~s}, 6 \mathrm{H}), 2.21(\mathrm{~m}, 2 \mathrm{H}), 1.73(\mathrm{~m}, 2 \mathrm{H}), 1.59(\mathrm{~m}, 2 \mathrm{H}), 1.40(\mathrm{~s}, 9 \mathrm{H})$, $1.30(\mathrm{~m}, 7 \mathrm{H}), 1.18(\mathrm{~m}, 6 \mathrm{H}) ;{ }^{13} \mathrm{C} \mathrm{NMR}\left(400 \mathrm{MHz}, \mathrm{CD}_{3} \mathrm{CN}\right) \delta 172.87,172.14,171.25$, $170.44,170.30,169.91,156.64,145.04,144.47,138.82,138.70,138.43,138.37,138.08$, $128.67,128.54,128.48,127.99,127.96,127.94,127.84,127.80,127.71,122.80,121.76$, $121.18,120.88,80.01,74.64,74.45,72.98,72.93,72.74,70.98,70.52,69.88,68.88$, $68.61,64.99,59.47,57.11,55.01,53.49,49.70,48.33,45.15,45.06,35.11,29.37,29.15$, $28.15,27.78,25.43,25.08,17.08,15.86,15.65,9.48,9.39$; HRMS (ESI) calcd for $\mathrm{C}_{78} \mathrm{H}_{104} \mathrm{O}_{14} \mathrm{~N}_{10}\left(\mathrm{M}^{2+}{ }_{-} \mathrm{TfO}\right)$ 702.3861, found: 702.3866 .

Compound 26c (imidazolium trimer 22 as support): faun powders. 100\% yield. M. P. 212-214 ${ }^{\circ} \mathrm{C}$, dec.; ${ }^{1} \mathrm{H}$ NMR $\left(500 \mathrm{MHz}, \mathrm{CD}_{3} \mathrm{CN}\right) \delta 7.52(\mathrm{~s}, 1 \mathrm{H}), 7.43(\mathrm{~d}, 1 \mathrm{H}, \mathrm{J}=5 \mathrm{~Hz})$, 7.37-7.24 (m, 29H), $5.75(\mathrm{~s}, 1 \mathrm{H}), 4.60-4.46(\mathrm{~m}, 9 \mathrm{H}), 4.40(\mathrm{~m}, 3 \mathrm{H}), 4.32-4.21(\mathrm{M}, 3 \mathrm{H})$, 4.12-4.02 (m, 16H), $3.99(\mathrm{~m}, 1 \mathrm{H}), 3.83(\mathrm{~m}, 1 \mathrm{H}), 3.76-3.70(\mathrm{~m}, 5 \mathrm{H}), 3.67(\mathrm{~m}, 1 \mathrm{H}), 3.59$ (m, 1H), $3.52(\mathrm{~s}, 1 \mathrm{H}), 2.59(\mathrm{~s}, 3 \mathrm{H}), 2.54(\mathrm{~s}, 3 \mathrm{H}), 2.51(\mathrm{~s}, 3 \mathrm{H}), 2.25(\mathrm{~m}, 4 \mathrm{H}), 2.15-2.06(\mathrm{~m}$, $2 \mathrm{H}), 1.41(\mathrm{~s}, 9 \mathrm{H}), 1.32(\mathrm{~d}, 3 \mathrm{H}, \mathrm{J}=7 \mathrm{~Hz}), 1.20(\mathrm{~m}, 6 \mathrm{H}) ;{ }^{13} \mathrm{C} \mathrm{NMR}\left(500 \mathrm{MHz}, \mathrm{CD}_{3} \mathrm{CN}\right) \delta$ $173.16,172.38,171.49,170.50,170.35,170.29,156.58,145.10,144.99,144.80,138.79$, $138.70,138.44,138.36,138.07,128.68,128.54,128.51,128.01,127.96,127.92,127.89$, $127.81,127.71,122.90,122.00,121.57,121.23,120.86,80.08,74.62,74.41,73.01$, $72.93,72.73,71.00,70.63,69.91,68.75,61.44,59.62,57.34,55.34,53.84,50.12,45.25$, $45.21,45.17,45.13,35.09,35.06,29.30,29.19,28.18,27.82,17.00,15.94,15.60,9.41$, 
9.39, 9.32, 9.31; HRMS (ESI) calcd for $\mathrm{C}_{82} \mathrm{H}_{109} \mathrm{O}_{14} \mathrm{~N}_{12}\left(\mathrm{M}^{3+}-3 \mathrm{TfO}\right)$ 495.2723, found: 495.2722 .

Compound 26d (imidazolium tetramer 23 as support): faun solid. 100\% yield. M. P. 213-215 ${ }^{\circ} \mathrm{C}$, dec.; ${ }^{1} \mathrm{H}$ NMR (500 MHz, $\left.\mathrm{CD}_{3} \mathrm{CN}\right) \delta 7.53$ (s, 1H), 7.43 (s, 1H), 7.35-7.29 (m, 31H), $5.77(\mathrm{~s}, 1 \mathrm{H}), 4.64-4.40(\mathrm{~m}, 12 \mathrm{H}), 4.26(\mathrm{~m}, 3 \mathrm{H}), 4.28-3.99(\mathrm{~m}, 20 \mathrm{H}), 3.83(\mathrm{~m}$, 1H), $3.73(\mathrm{~m}, 4 \mathrm{H}), 3.68(\mathrm{~m}, 2 \mathrm{H}), 3.60(\mathrm{~m}, 1 \mathrm{H}), 3.50(\mathrm{~m}, 1 \mathrm{H}), 2.59(\mathrm{~s}, 3 \mathrm{H}), 2.58(\mathrm{~s}, 3 \mathrm{H})$, $2.54(\mathrm{~s}, 3 \mathrm{H}), 2.51(\mathrm{~s}, 3 \mathrm{H}), 2.27(\mathrm{~m}, 6 \mathrm{H}), 2.08(\mathrm{~m}, 2 \mathrm{H}), 1.41(\mathrm{~s}, 9 \mathrm{H}), 1.32(\mathrm{~d}, 3 \mathrm{H}, \mathrm{J}=7$ $\mathrm{Hz}), 1.20(\mathrm{~d}, 3 \mathrm{H}, \mathrm{J}=6 \mathrm{~Hz}) ;{ }^{13} \mathrm{C} \mathrm{NMR}\left(400 \mathrm{MHz}, \mathrm{CD}_{3} \mathrm{CN}\right) \delta 173.00,172.24,171.35$, $170.35,170.19,170.15,156.48,145.02,144.92,144.71,138.72,138.62,138.37,138.29$, $137.98,128.63,128.54,128.49,128.47,128.28,128.02,127.96,127.92,127.88,127.83$, $127.79,127.76,127.67,122.86,121.97,121.72,121.53,121.20,120.82,80.17,74.70$, $74.46,73.89,73.10,73.02,72.82,71.09,70.76,70.72,70.00,68.83,68.62,62.18,61.54$ $59.74,58.02,57.47,55.38,53.98,50.29,45.41,45.34,45.28,35.26,29.49,29.37,28.51$, 28.38, 28.02, 17.20, 16.16, 15.84, 9.65, 9.56; HRMS (ESI) calcd for $\mathrm{C}_{89} \mathrm{H}_{120} \mathrm{O}_{14} \mathrm{~N}_{14}$ ( $\left.\mathrm{M}^{4+}-4 \mathrm{TfO}\right)$ 402.2271, found: 402.2273.

Compound 28 (imidazolium trimer 22 as support): To the flask charged with imidazolium trimer-bound peptide $26 \mathbf{c}(65.7 \mathrm{mg}, 0.034 \mathrm{mmol})$, hexa-amino-acid peptide 27 (91.8 mg, $0.083 \mathrm{mmol})$, HBTU (35.9 mg, $0.085 \mathrm{mmol})$, HOBT (13.1 mg, 0.085 mmol) was added dry acetonitrile $(6 \mathrm{~mL})$ and then diisopropylethylamine (DIPEA) (31 $\mu \mathrm{L}, 0.17 \mathrm{mmol})$. The reaction mixture was stirred at room temperature under the protection of nitrogen atmosphere for 31 hours and then concentrated by rotary evaporation under reduced pressure. The residue was added with diethyl ether and then transferred into conical vial. The mixture was subjected to centrifugation and the top 
liquid phase was decanted. The solid phase was washed with diethyl ether $(3 \mathrm{~mL})$ twice, $\mathrm{CH}_{2} \mathrm{Cl}_{2}(3 \mathrm{~mL})$ twice, THF (3 mL) twice and then ether $(3 \mathrm{~mL})$ once, dried in vacuo to give the product $\mathbf{2 8}$ as faun powder (93.5 $\mathrm{mg}, 95 \%$ yield).

${ }^{1} \mathrm{H}$ NMR $\left(800 \mathrm{MHz}, \mathrm{CD}_{3} \mathrm{CN}\right) \delta 7.92(\mathrm{~s}, 1 \mathrm{H}), 7.78(\mathrm{~s}, 1 \mathrm{H}), 7.71(\mathrm{~s}, 1 \mathrm{H}), 7.60(\mathrm{~m}, 3 \mathrm{H})$, 7,51 (m, 4H), 7.42-7.20 (m, 38H), 7.20-6.60 (broad, 20H), $5.81(\mathrm{~d}, 1 \mathrm{H}, \mathrm{J}=6.4 \mathrm{~Hz}), 4.57$ (m, 4H), 4.53-4.37 (m, 17H), $4.32(\mathrm{~m}, 3 \mathrm{H}), 4.22-4.04(\mathrm{~m}, 27 \mathrm{H}), 3.98(\mathrm{~m}, 2 \mathrm{H}), 3.84-3.68$ (m, 14H, $3.62(\mathrm{~m}, 3 \mathrm{H}), 3.59(\mathrm{~m}, 2 \mathrm{H}), 3.46(\mathrm{~m}, 2 \mathrm{H}), 2.55(\mathrm{~s}, 3 \mathrm{H}), 2.53(\mathrm{~s}, 3 \mathrm{H}), 2.51(\mathrm{~s}$, 3H), $2.24(\mathrm{~m}, 2 \mathrm{H}$, overlap), $1.40(\mathrm{~s}, 9 \mathrm{H}), 1.38(\mathrm{~d}, 3 \mathrm{H}, \mathrm{J}=8 \mathrm{~Hz}), 1.32(\mathrm{~d}, 3 \mathrm{H}), 1.20(\mathrm{~m}$, $6 \mathrm{H}), 1.56(\mathrm{~m}, 6 \mathrm{H})$; HRMS (ESI) calcd for $\mathrm{C}_{137} \mathrm{H}_{173} \mathrm{O}_{25} \mathrm{~N}_{18}\left(\mathrm{M}^{3+}-3 \mathrm{TfO}\right)$ 823.4267, found: 823.4262.

Compound 29 (imidazolium trimer 22 as support): To the flask charged with imidazolium trimer-bound peptide 25 (51.6 $\mathrm{mg}, 0.021 \mathrm{mmol}$ ), hexa-amino-acid peptide 27 (50.2 mg, $0.045 \mathrm{mmol})$, HBTU (18.7 mg, $0.049 \mathrm{mmol})$, HOBT (6.8 mg, $0.049 \mathrm{mmol})$ was added dry acetonitrile $(15 \mathrm{~mL})$ and then diisopropylethylamine (DIPEA) $(21 \mu \mathrm{L}$, $0.12 \mathrm{mmol}$ ). The reaction mixture was stirred at room temperature under the protection of nitrogen atmosphere for 31 hours and then concentrated by rotary evaporation under reduced pressure. The residue was added with diethyl ether and then transferred into conical vial. The mixture was subjected to centrifugation and the top liquid phase was decanted. The solid phase was washed with diethyl ether $(3 \mathrm{~mL})$ twice, $\mathrm{CH}_{2} \mathrm{Cl}_{2}(3 \mathrm{~mL})$ twice, THF (3 mL) twice and then ether $(3 \mathrm{~mL})$ once, dried in vacuo to give the product 29 as faun powder (70.8 $\mathrm{mg}, 99 \%$ yield).

HRMS (ESI) calcd for $\mathrm{C}_{161} \mathrm{H}_{202} \mathrm{O}_{30} \mathrm{~N}_{21}\left(\mathrm{M}^{3+}\right.$-3TfO) 969.8303, found: 969.8291 . 
General procedures to cleave peptides from imidazolium salt supports: To the flask charged with imidazolium salt-bound peptide (1 equiv.) was added THF and $\mathrm{H}_{2} \mathrm{O}$ $(\mathrm{V} / \mathrm{V}=3: 1)(5 \mathrm{ml} / 50 \mathrm{mg}$ of the substrate). The mixture was stirred at room temperature for a few minutes to completely dissolve the supported peptide into the mixed solvents. Aqueous $\mathrm{LiOH}(0.1 \mathrm{M}, 1$ equiv.) or $\mathrm{NaOH}(1.0 \mathrm{M}, 1$ equiv.) solution was then added. The reaction mixture was stirred at room temperature for 20 hours. The volatile solvent was removed by rotary evaporation under reduced pressure and the residue was added with water and then aqueous $\mathrm{HCl}(0.1 \mathrm{M})$ to adjust the $\mathrm{pH}$ to 5 . The white precipitate was filtered and washed with water for 3 times and ether for 3 times to give the product as faun powder.

Compound 27: white powder. $81 \%$ yield. M. P. $167-169{ }^{\circ} \mathrm{C} ;[\alpha]_{\mathrm{D}}{ }^{20}=33.0(\mathrm{c}=1$, in THF); ${ }^{1} \mathrm{H}$ NMR (500 MHz, $\left.\mathrm{CD}_{3} \mathrm{COCD}_{3}\right) \delta 7.75(\mathrm{~s}, 1 \mathrm{H}), 7.70$ 9s, 1H), $7.62(\mathrm{~d}, 1 \mathrm{H}, \mathrm{J}=7.5$ Hz), $7.51(\mathrm{~d}, 1 \mathrm{H}, \mathrm{J}=7.0 \mathrm{~Hz}), 7.42(\mathrm{~d}, 1 \mathrm{H}, \mathrm{J}=9.0 \mathrm{~Hz}), 7.35-7.21(\mathrm{~m}, 20 \mathrm{H}), 6.11(\mathrm{~d}, 1 \mathrm{H}, \mathrm{J}$ $=7.5 \mathrm{~Hz}), 4.73(\mathrm{~m}, 1 \mathrm{H}), 4.63-4.43(\mathrm{~m}, 15 \mathrm{H}), 4.23(\mathrm{~m}, 2 \mathrm{H}), 4.10(\mathrm{~s}, 1 \mathrm{H}), 3.86(\mathrm{~m}, 3 \mathrm{H})$, $3.73(\mathrm{~m}, 1 \mathrm{H}), 3.67(\mathrm{~m}, 1 \mathrm{H}), 3.60(\mathrm{~m}, 1 \mathrm{H}), 1.40(\mathrm{~s}, 9 \mathrm{H}), 1.30(\mathrm{~d}, 3 \mathrm{H}, \mathrm{J}=7.0 \mathrm{~Hz}), 1.21(\mathrm{~m}$, $6 \mathrm{H}) ;{ }^{13} \mathrm{C}$ NMR (500 MHz, THF-d ${ }^{4}$, concentrated) $\delta 174.18,173.87,172.31,170.93$, $171.10,157.77,141.15,140.55,130.02,129.96,129.87,129.50,129.08,128.96,80.42$, $77.61,74.77,74.68,73.25,72.85,72.48,72.17,60.68,58.98,55.53,55.00,54.89,50.75$, 29.78, 20.56, 18.12, 17.61; HRMS (ESI) calcd for $\mathrm{C}_{60} \mathrm{H}_{75} \mathrm{O}_{14} \mathrm{~N}_{6}\left(\mathrm{M}+\mathrm{H}^{+}\right)$1103.5335, found: 1103.5313 .

Nonapeptide (cleaved from Compound 25): M. P. $236-238{ }^{\circ} \mathrm{C} .{ }^{1} \mathrm{H}$ NMR $(500 \mathrm{MHz}$, DMSO-d $\left.^{6}\right) \delta 8.28(\mathrm{~s}, 1 \mathrm{H}), 8.20(\mathrm{~d}, 1 \mathrm{H}, \mathrm{J}=7.0 \mathrm{~Hz}), 8.05(\mathrm{~d}, 1 \mathrm{H}, \mathrm{J}=7.5 \mathrm{~Hz}), 7.97(\mathrm{~m}$, 2H), $7.91(\mathrm{~s}, 1 \mathrm{H}), 7.26(\mathrm{~m}, 28 \mathrm{H}), 6.96(\mathrm{~d}, 1 \mathrm{H}, \mathrm{J}=8.0 \mathrm{~Hz}), 4.69-4.64(\mathrm{~m}, 3 \mathrm{H}), 4.58-4.52$ 
(m, 5H), $4.43(\mathrm{~m}, 15 \mathrm{H}), 4.03(\mathrm{~m}, 2 \mathrm{H}), 3.96(\mathrm{~m}, 2 \mathrm{H}), 3.60-3.52(\mathrm{~m}, 8 \mathrm{H}), 1.34(\mathrm{~s}, 9 \mathrm{H}), 1.15$ (d, 6H), $1.02(\mathrm{~m}, 9 \mathrm{H}) ;{ }^{13} \mathrm{C}$ NMR (500 MHz, DMSO-d $\left.{ }^{6}\right) \delta 173.45,172.57,172.07,170.51$, $170.27,170.11,170.00,169.26,155.66,139.31,139.24,138.79,138.76,138.70,128.80$ $128.77,128.67,128.17,128.14,128.05,128.00,127.83,78.70,75.80,75.72,72.76$, $72.70,71.17,70.89,70.58,70.47,58.41,56.91,53.40,53.12,50.26,49.27,45.30,28.85$, 19.14, 18.85, 17.00, 16.78. HRMS (ESI) calcd for $\mathrm{C}_{84} \mathrm{H}_{103} \mathrm{O}_{19} \mathrm{~N}_{9}\left(\mathrm{M}+\mathrm{Na}^{+}\right)$1564.7262, found: 1564.7265 .

Dodecapeptide (cleaved from Compound 28): ${ }^{1} \mathrm{H}$ NMR (400 MHz, DMSO- $\left.{ }^{6}\right) \delta 8.32-$ $8.21(\mathrm{~m}, 3 \mathrm{H}), 8.09-8.03(\mathrm{~m}, 3 \mathrm{H}), 7.91(\mathrm{~d}, 1 \mathrm{H}, \mathrm{J}=8.0 \mathrm{~Hz}), 7.62(\mathrm{~m}, 2 \mathrm{H}), 7.24(\mathrm{~m}, 40 \mathrm{H})$, $6.58(\mathrm{~m}, 1 \mathrm{H}, \mathrm{J}=8.8 \mathrm{~Hz}), 4.68(\mathrm{~m}, 2 \mathrm{H}), 4.55(\mathrm{~m}, 5 \mathrm{H}), 4.40-4.36(\mathrm{~m}, 21 \mathrm{~h}), 4.13(\mathrm{~m}, 3 \mathrm{H})$, $3.97(\mathrm{~m}, 3 \mathrm{H}), 3.84(\mathrm{~m}, 1 \mathrm{H}), 3.56(\mathrm{~m}, 11 \mathrm{H}), 1.36(\mathrm{~m}, 9 \mathrm{H}), 1.57(\mathrm{~m}, 6 \mathrm{H}), 1.03(\mathrm{~m}, 12 \mathrm{H})$.

The high-resolution mass spectra (HRMS) were obtained after debenzylation of the dodecapeptide. The deprotection of benzyl group was carried out by palladium-catalyzed hydrogenation in methanol. After filtration to remove Pd-C and rotary evaporation of methanol under reduced pressure, the product residue was washed with diethyl ether for three times to give the unprotected dodecapeptide in 90\% yield. HRMS (ESI) calcd for $\mathrm{C}_{45} \mathrm{H}_{76} \mathrm{O}_{25} \mathrm{~N}_{12}\left(\mathrm{M}^{2-}\right)$ 592.2527, found: 592.2530; calcd for $\mathrm{C}_{45} \mathrm{H}_{77} \mathrm{O}_{25} \mathrm{~N}_{12}\left(\mathrm{M}^{-}\right)$1185.5128, found: 1185.5089 .

General procedures to recover imidazolium oligomer supports after the cleavage of peptides: After filtration to remove the oligopeptide, the aqueous phase was collected and the water was removed under freeze-dry conditions. The white solid obtained was added with acetonitrile and then filtered to remove insoluble inorganic salt. The organic phase was collected and the solvent was removed by rotary evaporation. The residue was 
washed with diethyl ether to give the imidazolium oligomer as solid in the 80-90\% recovery yields. The recovered imidazolium oligomer had the same ${ }^{1} \mathrm{H}$ and ${ }^{13} \mathrm{C}$ NMR spectra as the freshly synthesized materials.

Table 1. Onset decomposing temperatures (ODTs) $\left({ }^{\circ} \mathrm{C}\right)$ and residue percentages (RPs) (\%) of the samples according to TGA.

\begin{tabular}{cccccccc}
\hline Entry & Sample & ODT $\left({ }^{\circ} \mathrm{C}\right)$ & $\mathrm{RP}(\%)$ & Entry & Sample & ODT $\left({ }^{\circ} \mathrm{C}\right)$ & $\mathrm{RP}(\%)$ \\
\hline 1 & $\mathbf{1}$ & 80.6 & 0.18 & 10 & $\mathbf{9}$ & 212.2 & 1.89 \\
2 & $\mathbf{3}$ & 287.8 & 1.53 & 11 & $\mathbf{1 0}$ & 277.8 & 0.50 \\
3 & $\mathbf{4}$ & 293.9 & 1.71 & 12 & $\mathbf{7}$ & 252.3 & 0.17 \\
4 & $\mathbf{6}$ & 329.6 & 1.38 & 13 & $\mathbf{1 2}$ & 318.9 & 2.10 \\
5 & $\mathbf{1 1}$ & 326.2 & 1.76 & 14 & $\mathbf{1 4}$ & 291.8 & 0.50 \\
6 & $\mathbf{8}$ & 351.6 & 0.59 & 15 & $\mathbf{2 0}$ & 317.0 & 0.17 \\
7 & $\mathbf{1 3}$ & 336.4 & 0.58 & 16 & $\mathbf{1 6}$ & 296.5 & 0.19 \\
8 & $\mathbf{2}$ & 215.8 & 0.10 & 17 & $\mathbf{1 7}$ & 310.4 & 1.40 \\
9 & $\mathbf{5}$ & 239.4 & 0.59 & 18 & $\mathbf{1 9}$ & 337.9 & 2.21 \\
\hline
\end{tabular}

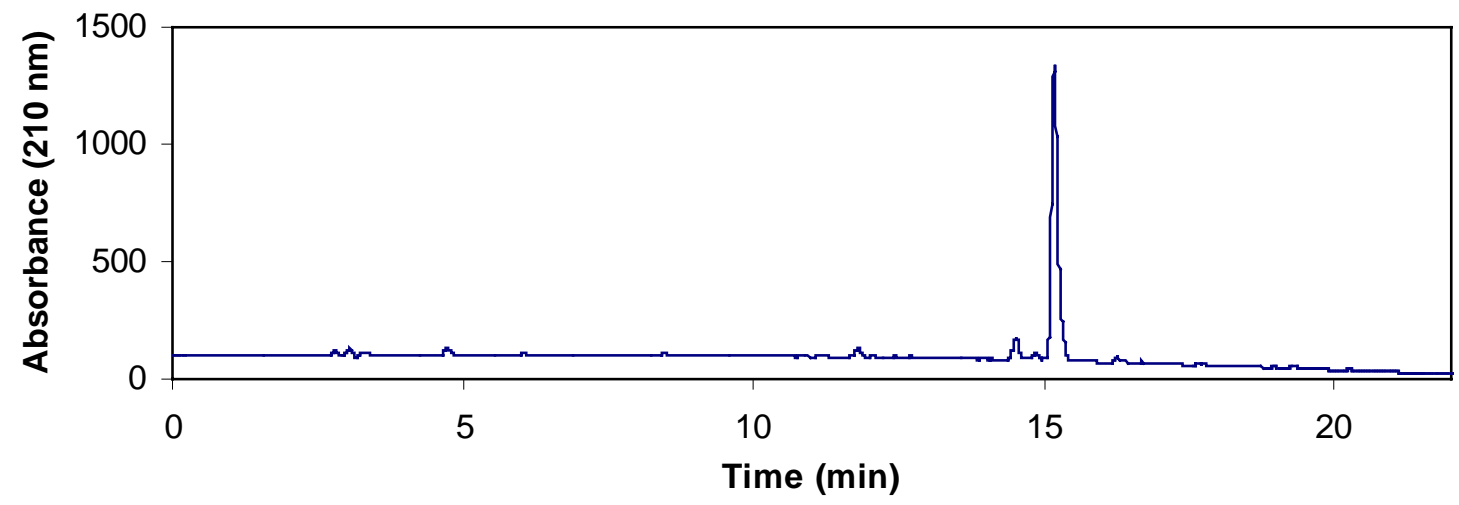

Figure 1. HPLC analysis of Compound 27, cleaved from Compound 26c. The small 
peaks at 3 min are due to TFA concentration change of the eluent because of TFA-free sample injection. 
$H X-I I 1-C-1-2-P-1$

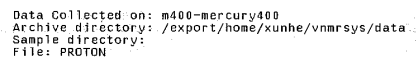

Pulse Sequence: s2pul

Solvent: $020 \mathrm{C} / 298.1 \mathrm{~K}$

Relax. delay 1.000 sec

8 repet itions
OBSERVE H1, 400.1255945 MH

DATA PROCESSING
FT Size 32768
Total time

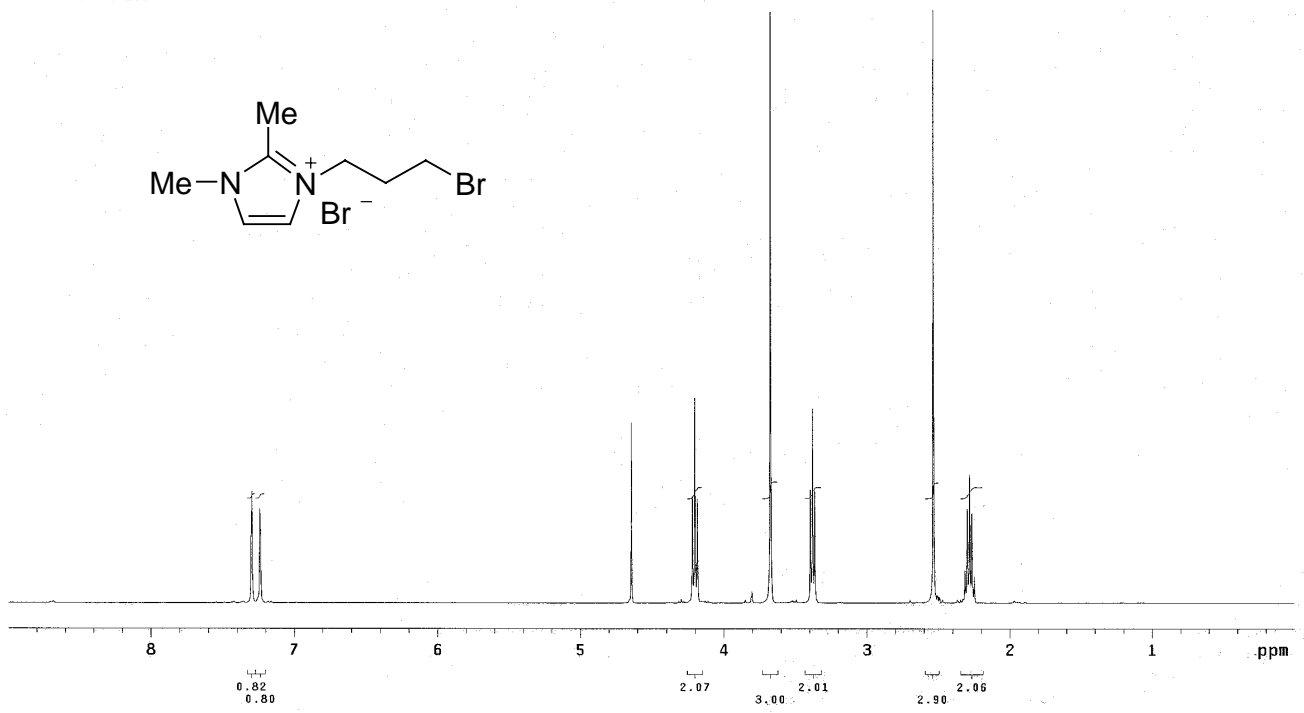

HX-III-C-2-1-P-5-C13

Data collected on: maj0-mercury 400
Archive directory: /export/home/xunhe/vnmrsys/data
Sample directory:

Pulse Sequence: s2pur

Solvent: $\mathrm{O}_{20} \mathrm{C} / 298.1 \mathrm{~K}$

Relax. delay $1.000 \mathrm{sec}$
Pulse 45.0 degrees

Acq t ime $1.199 \mathrm{sec}$
Width 25125.6

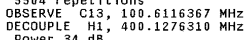

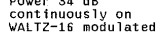

WALLZ-16 modu lated
DATA PROCESSTEG
Line broadening $1.0 \mathrm{~Hz}$

FT Size $65536 \mathrm{hr}, 35 \mathrm{~min}$
Total
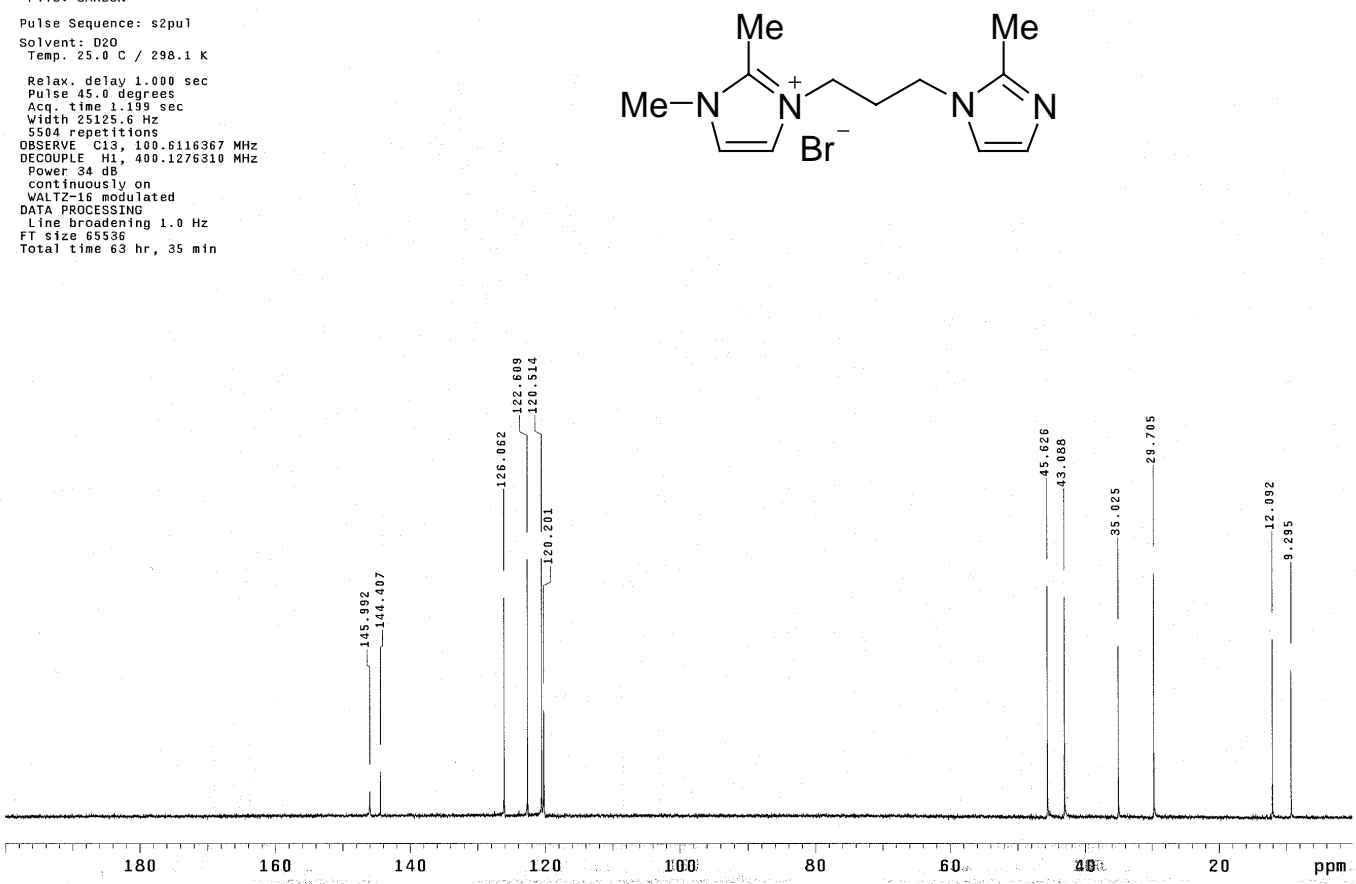


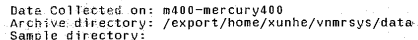

Sample director
File: PROTON

Pulse Sequence: s2pul

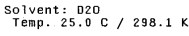

Relax. delay $1.000 \mathrm{se}$
Pulse 45.0 degrees

8 repet it ions
OBSERVE H1

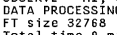
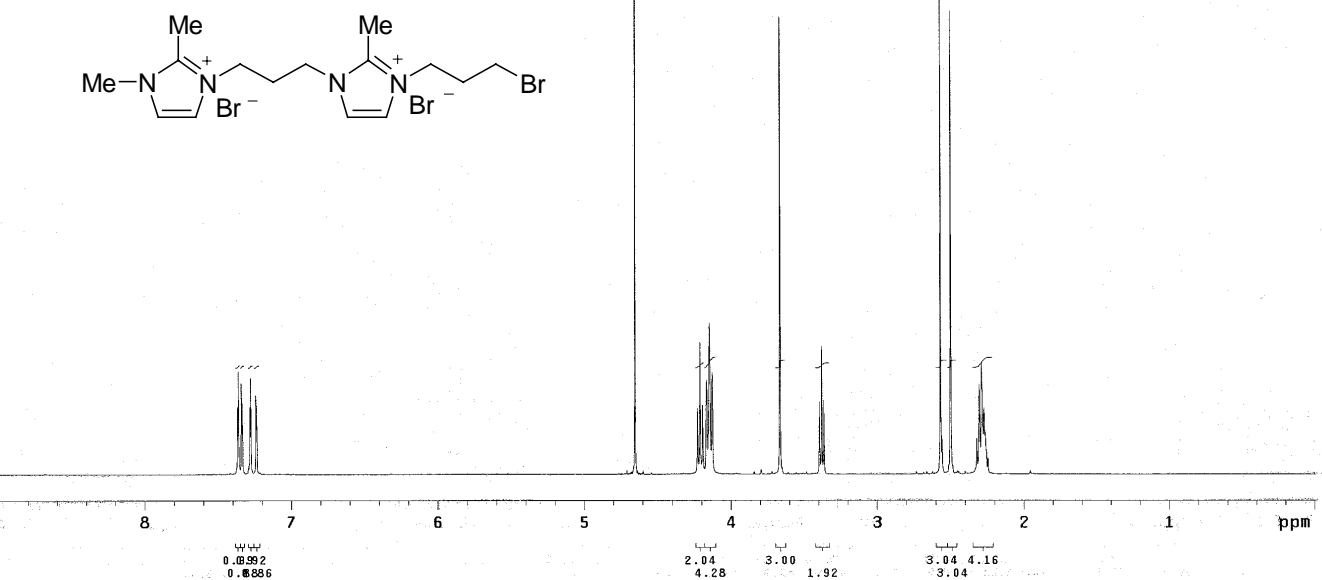

HX-III-C-5-1-P-5

Data collected on: m400-mercury 400
Archive directory: /export/home/xunhe/vnmrsys/data

Arample directory:

Pulse sequence: $\mathrm{s} 2 \mathrm{pu}$

Solvent: $020 \mathrm{C} / 298.1 \mathrm{~K}$
Temp. $25.0 \mathrm{C} / 29.1 \mathrm{~K}$

Relax. delay $1.000 \mathrm{~s}$
Pulse 45.0 degrees
Acq. time $1.998 \mathrm{sec}$
Widith $6410.3 \mathrm{~Hz}$

OBSERVE H1, $400.1255945 \mathrm{MHZ}$

OATA PROCESING
FT SIZE 32768

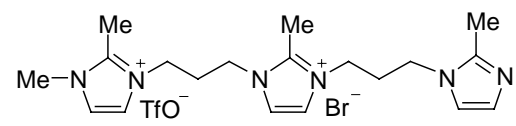

Total time $0 \mathrm{~min}$

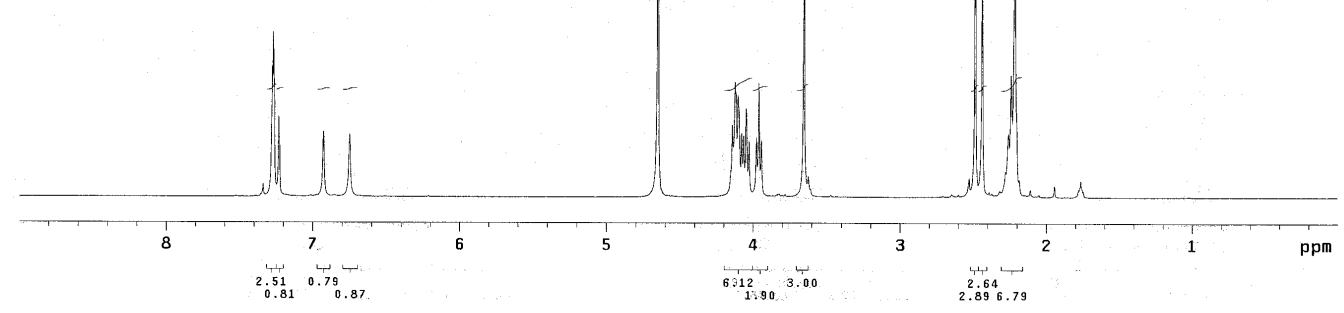



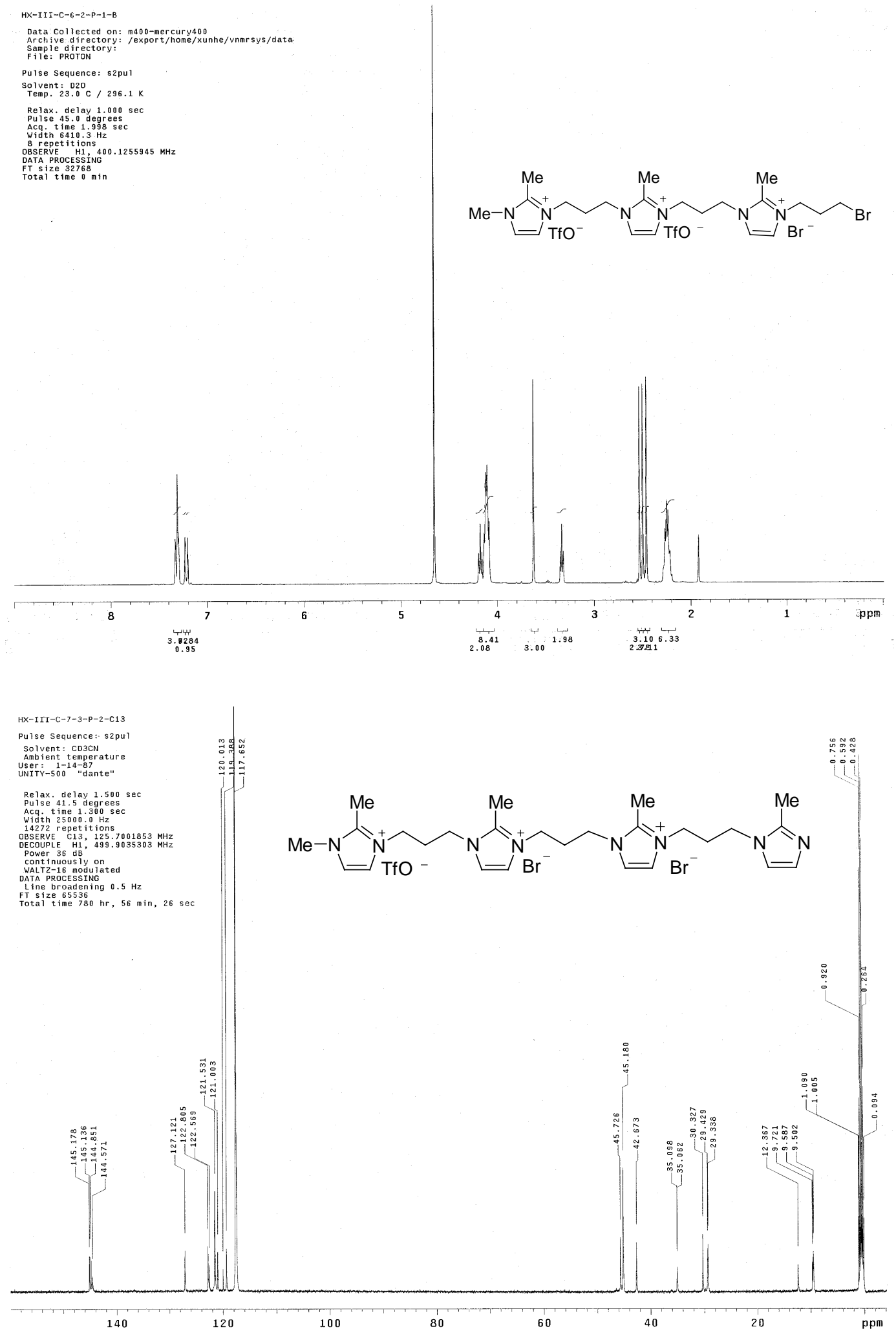


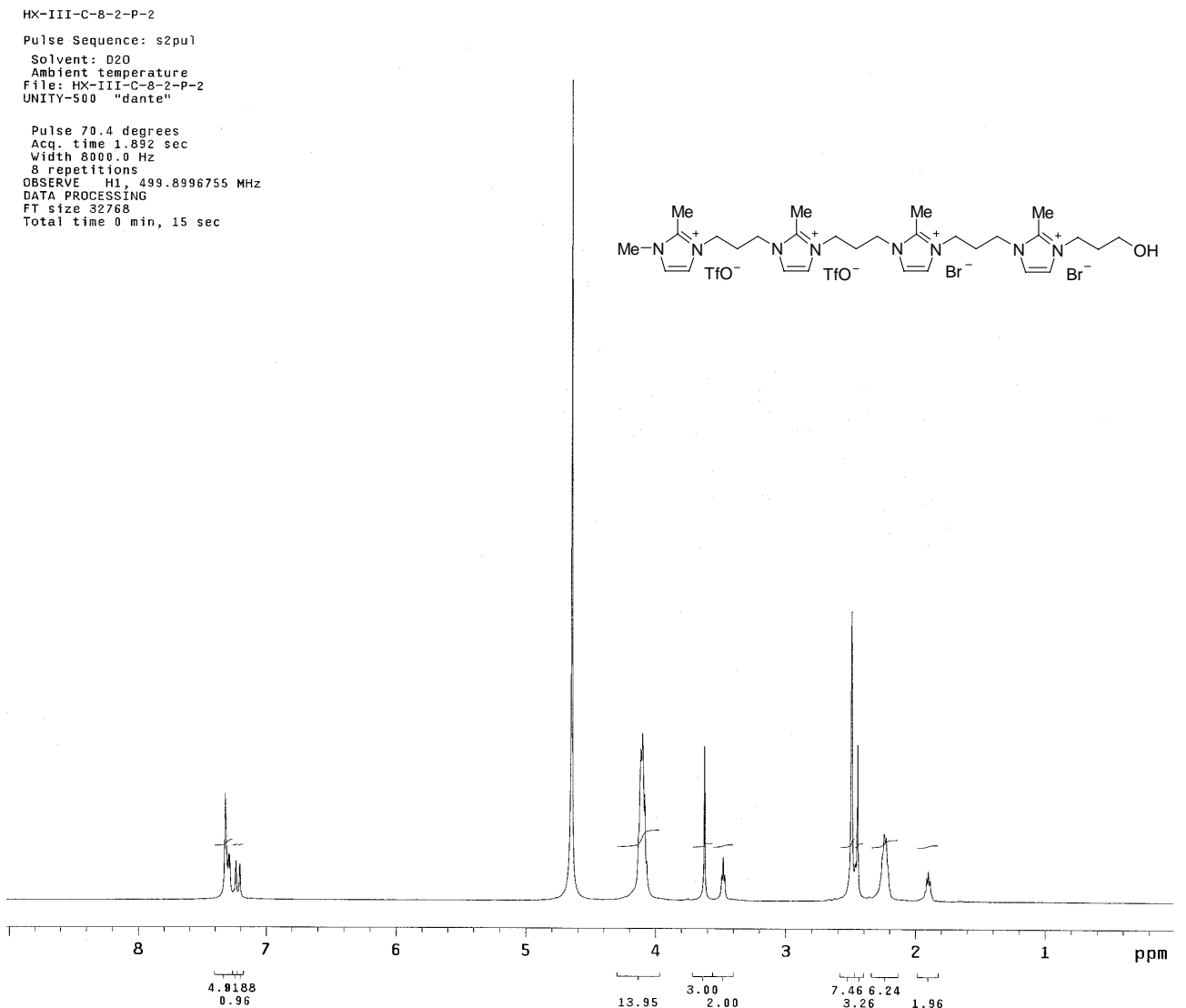

Pulse Sequence: $s 2$

Ambient temperature

Width $8000.0 \mathrm{~Hz}$

DBSERVE H1, 499.8996755 MHz

FT size 32768
Total time $0 \mathrm{~min}, 15 \mathrm{sec}$

X-III-E-5-2-P-2
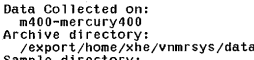

sample directory:

File: HX-III-E-5-2-P-2

Pulse Sequence: $52 \mathrm{pu}$
Solvent: $C D 3 C N$

Relax- delay $1.000 \mathrm{sec}$
Pulse 92.6 degrees

Acc. time $1.993 \mathrm{sec}$

Width $6006.0 \mathrm{~Hz}$
8 repetitions

BSERVE H1, 400.1240771

FT size 32768
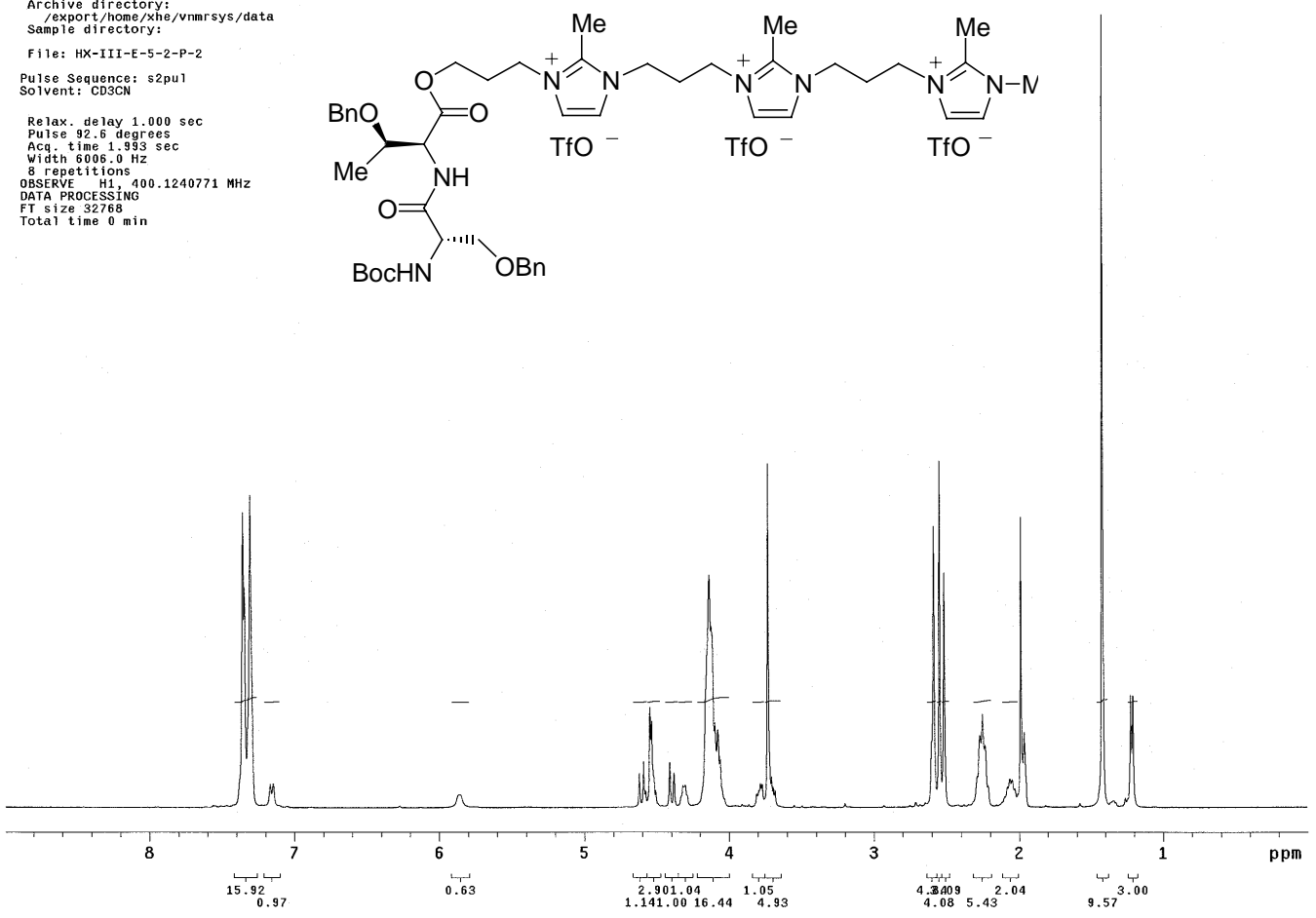


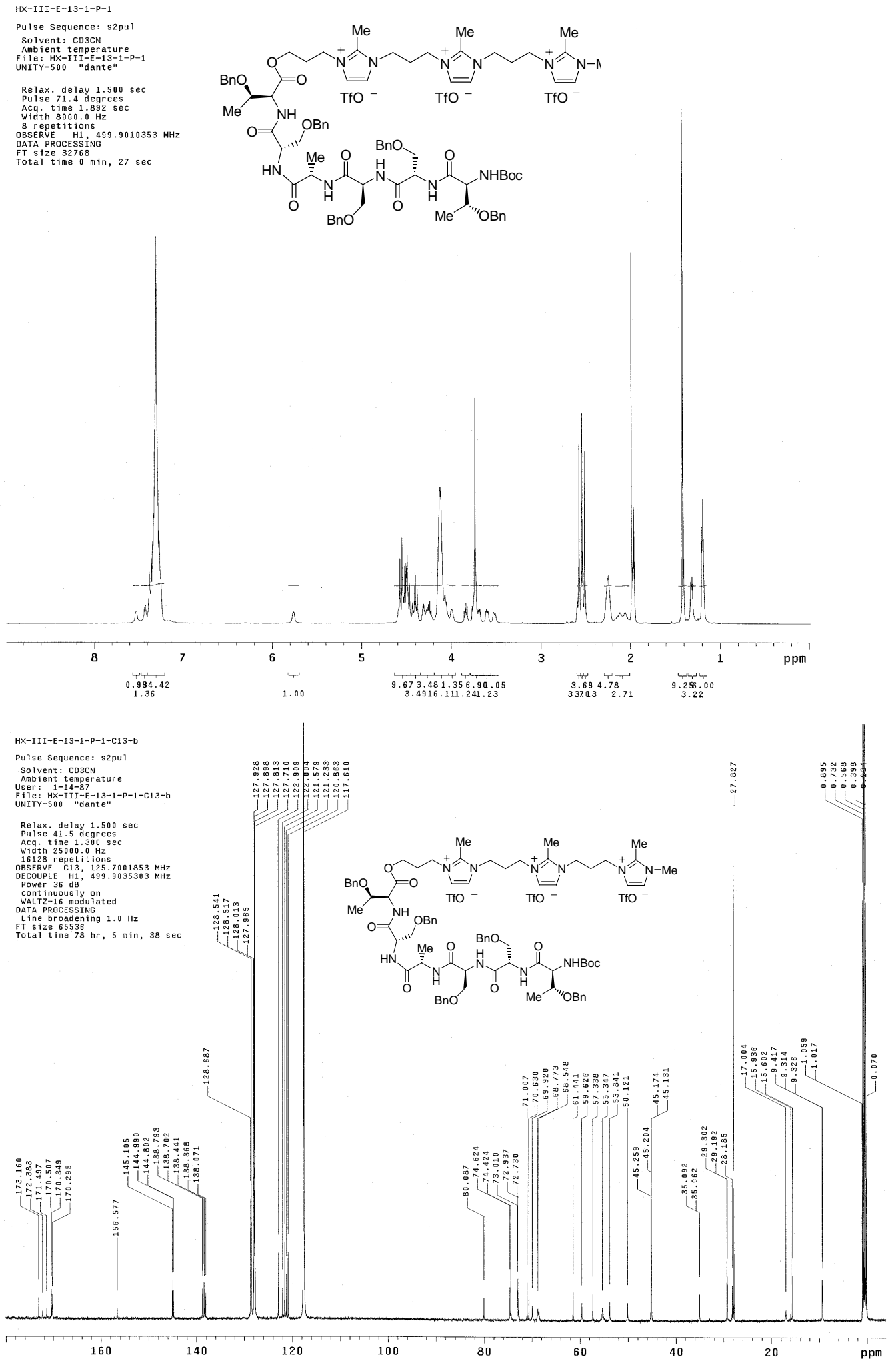



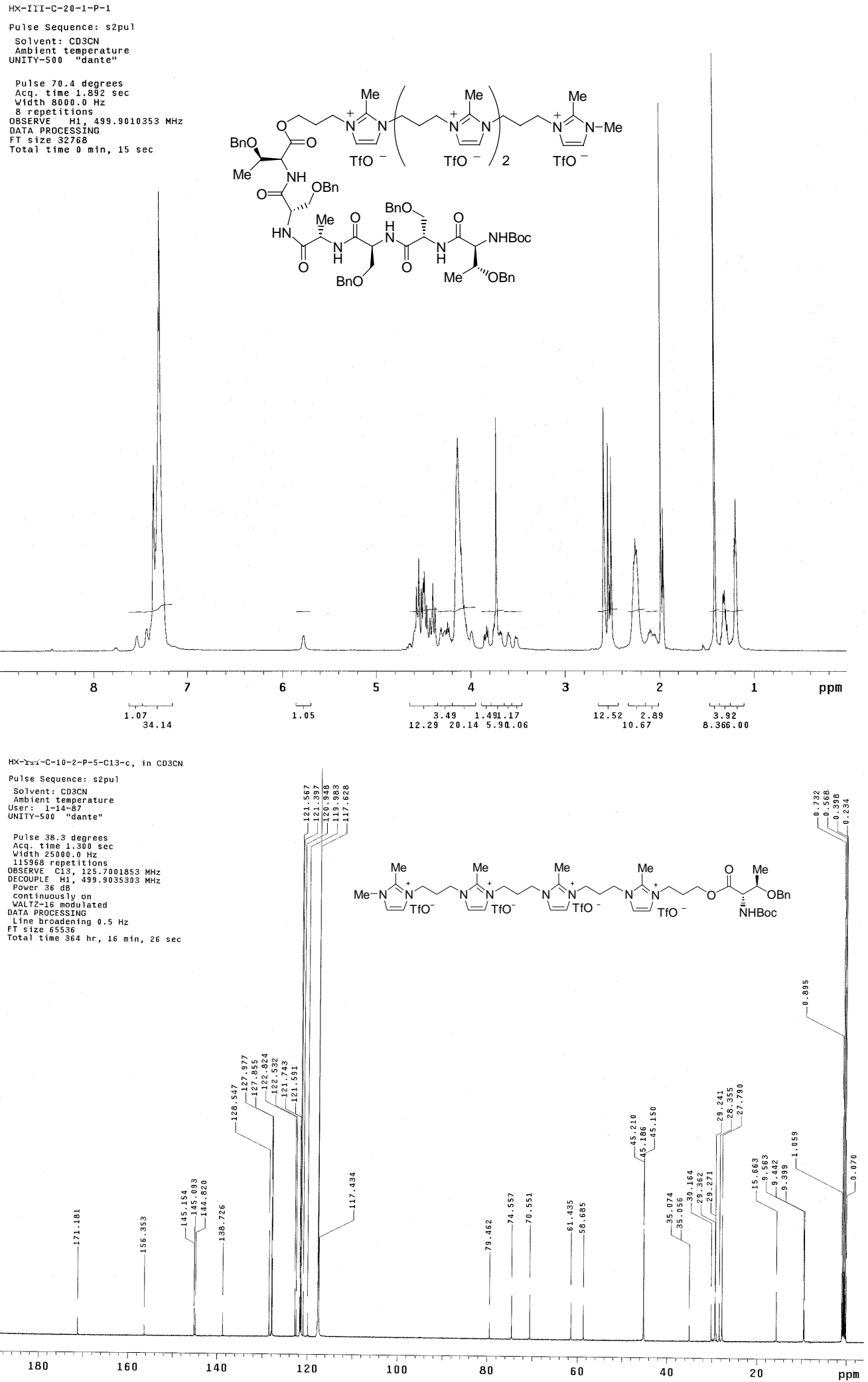
HX-III-A-6-4-P-2-b

Pulse Sequence: s2pul

Solvent: $\operatorname{coc} 13$
Ambient
UNITY-500 temperature

Pulse 70.4 degrees

Acc. time 1.892
Width $8000.0 \mathrm{~Hz}$
8 repetitions

OBSERVE H1, 499.8983908 MH

TT size 32768
Total time $0 \mathrm{~min}, 15 \mathrm{sec}$<smiles>Cc1n(C)cc[n+]1CCCOC(=O)[C@H](NC(=O)[C@H](COCc1ccccc1)NC(=O)OCc1ccccc1)[C@@H](C)OCc1ccccc1</smiles>

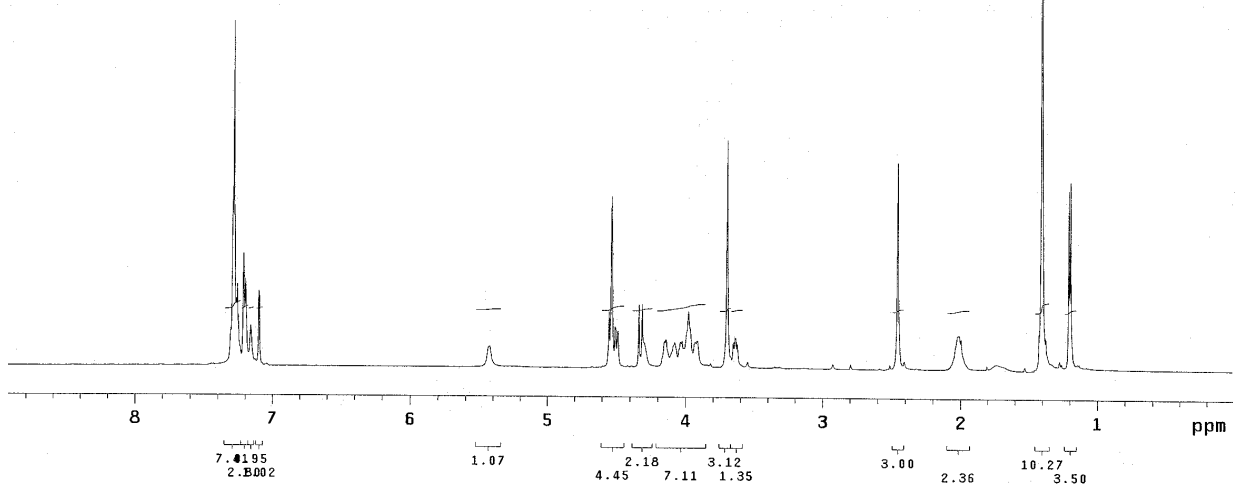

HX-III-A-14-1-P-2

Pulse Sequence: s2pul Solvent: COC13
Ambient temperature
UNITY-500 idante"

Pulse 70.4 degrees
Acq time $1.892 \mathrm{sec}$
Width $8000.0 \mathrm{~Hz}$
grepetitions

OBSERVE H1, $499.8983908 \mathrm{MHZ}$

ST size 32768
Total time $0 \mathrm{~min}, 15 \mathrm{sec}$
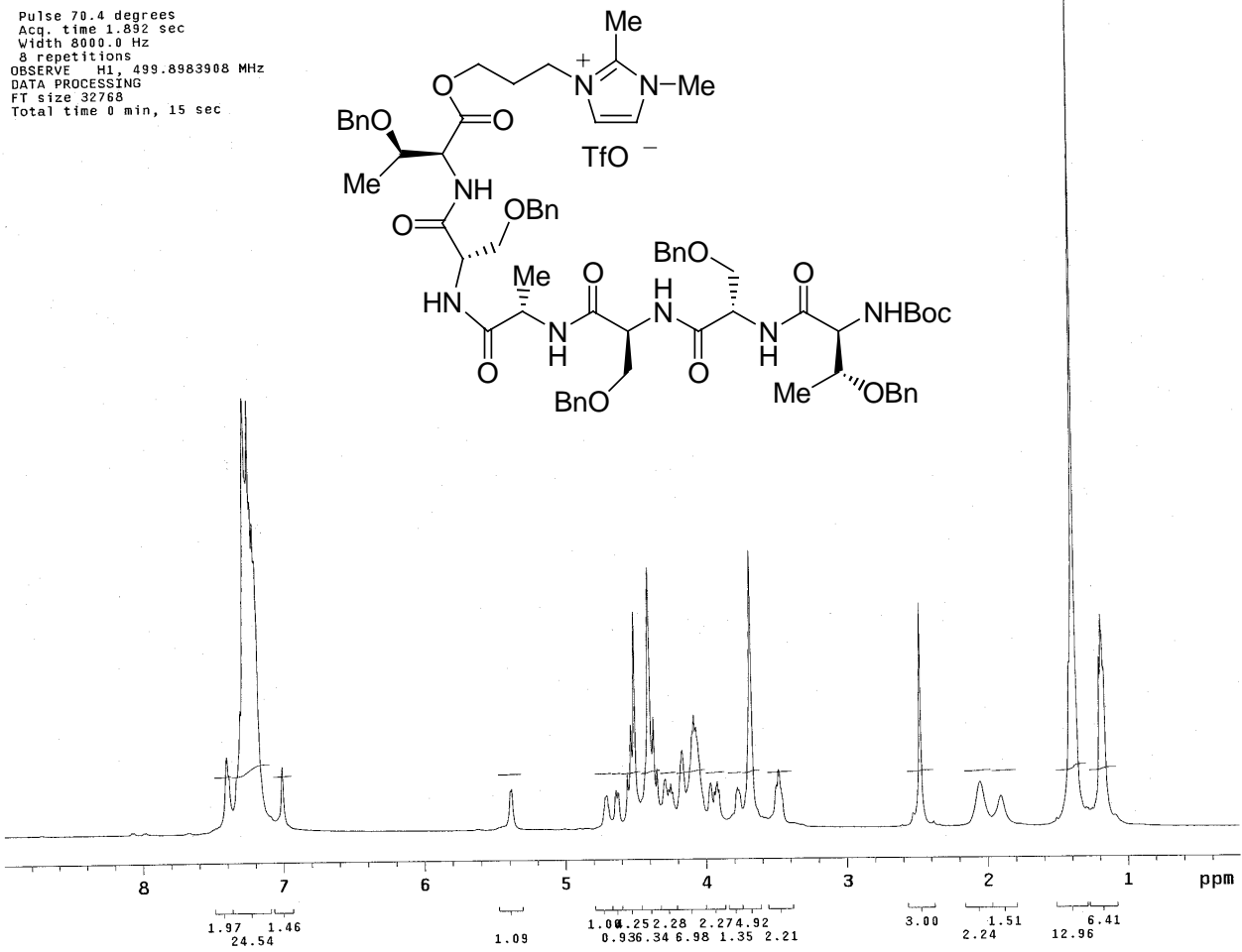


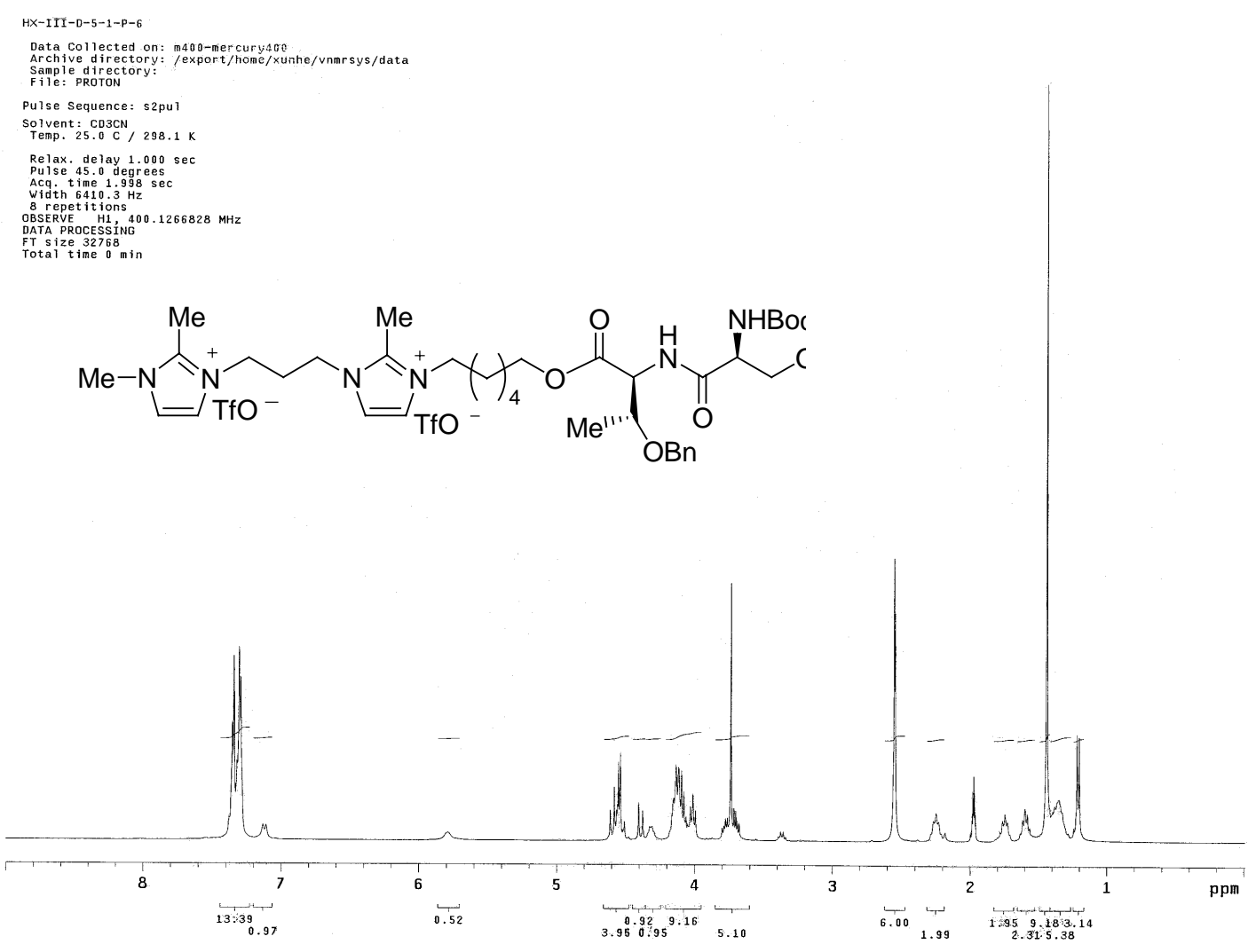

$H X-I I I-0-8-2-p-1$

Data collected ons, mu00-mercury400
Archive directory $=/$ export /home/ $\times$ unhe/vnirs sys/data Aramive directory:
Sile: pRoToN

Pulse Sequence: s2pur

Solvent: $\mathrm{CD} C \mathrm{CN}$

Relax. delay $1.000 \mathrm{sec}$
Pulse 45.0 degrees

Acct time $1.998 \mathrm{sec}$
Width $6410.3 \mathrm{~Hz}$

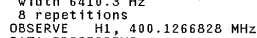

DATA PROCESSING

DATA PROCESSING
To Size 327888 tal
Totame 0 in in
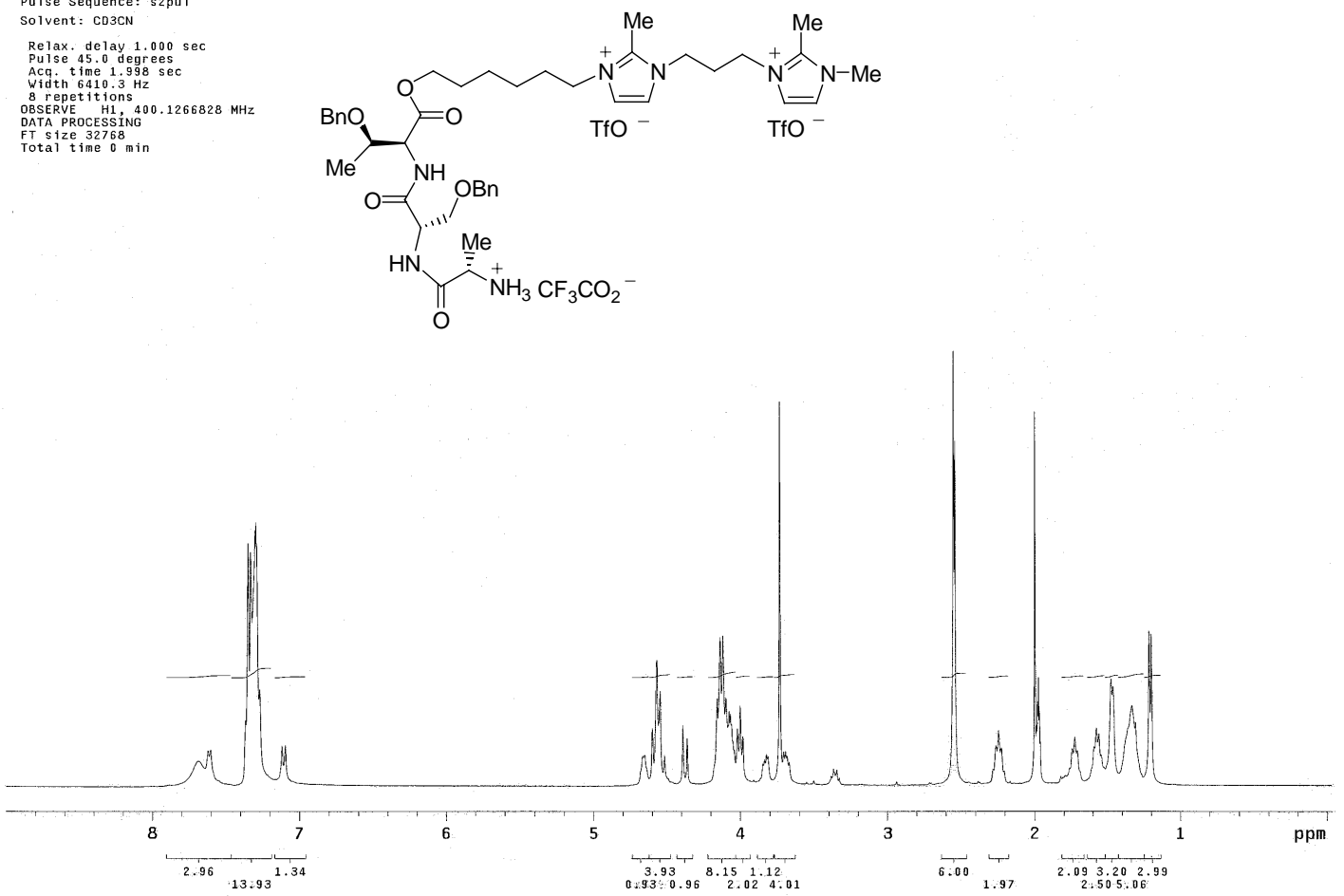

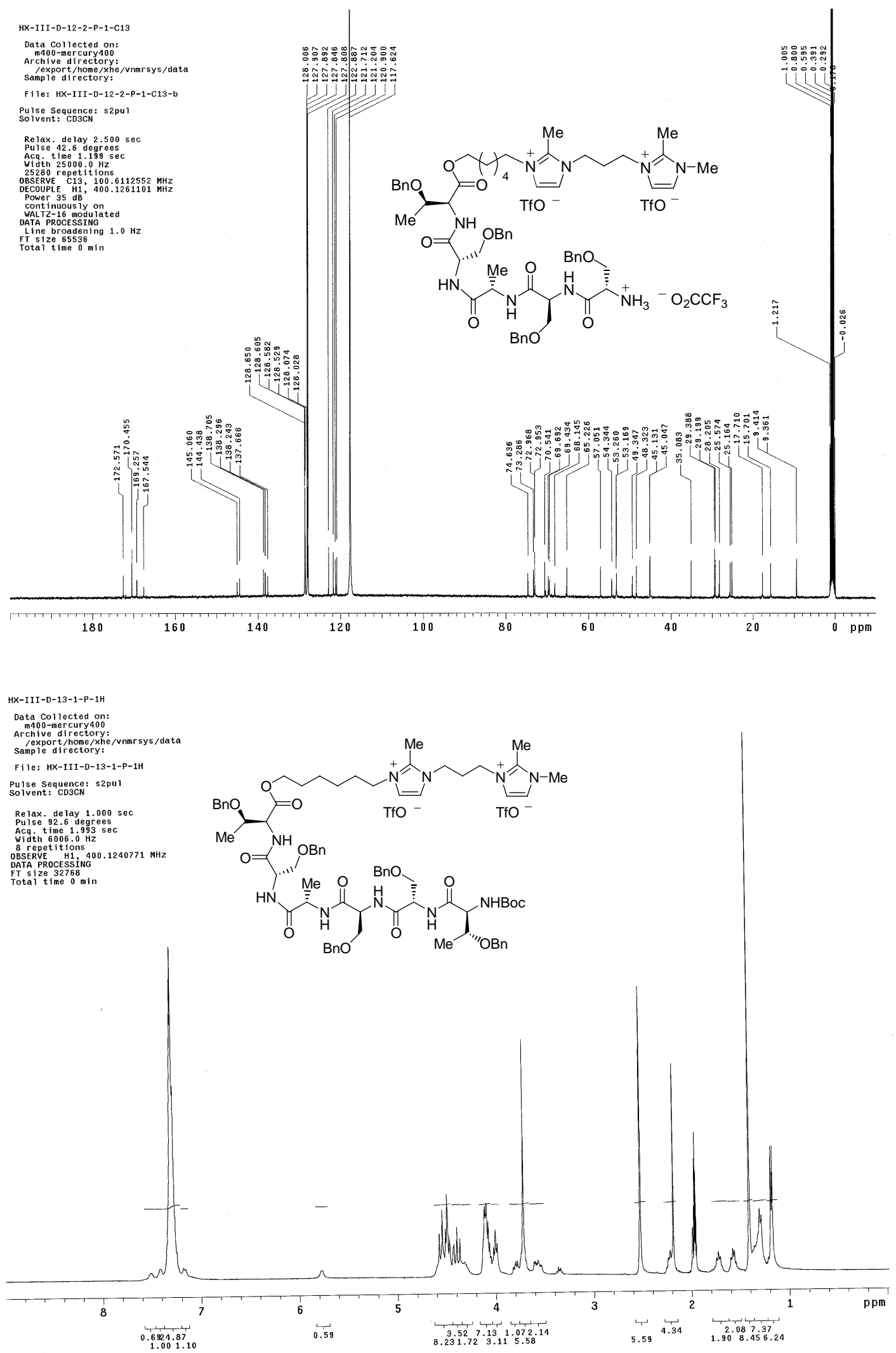


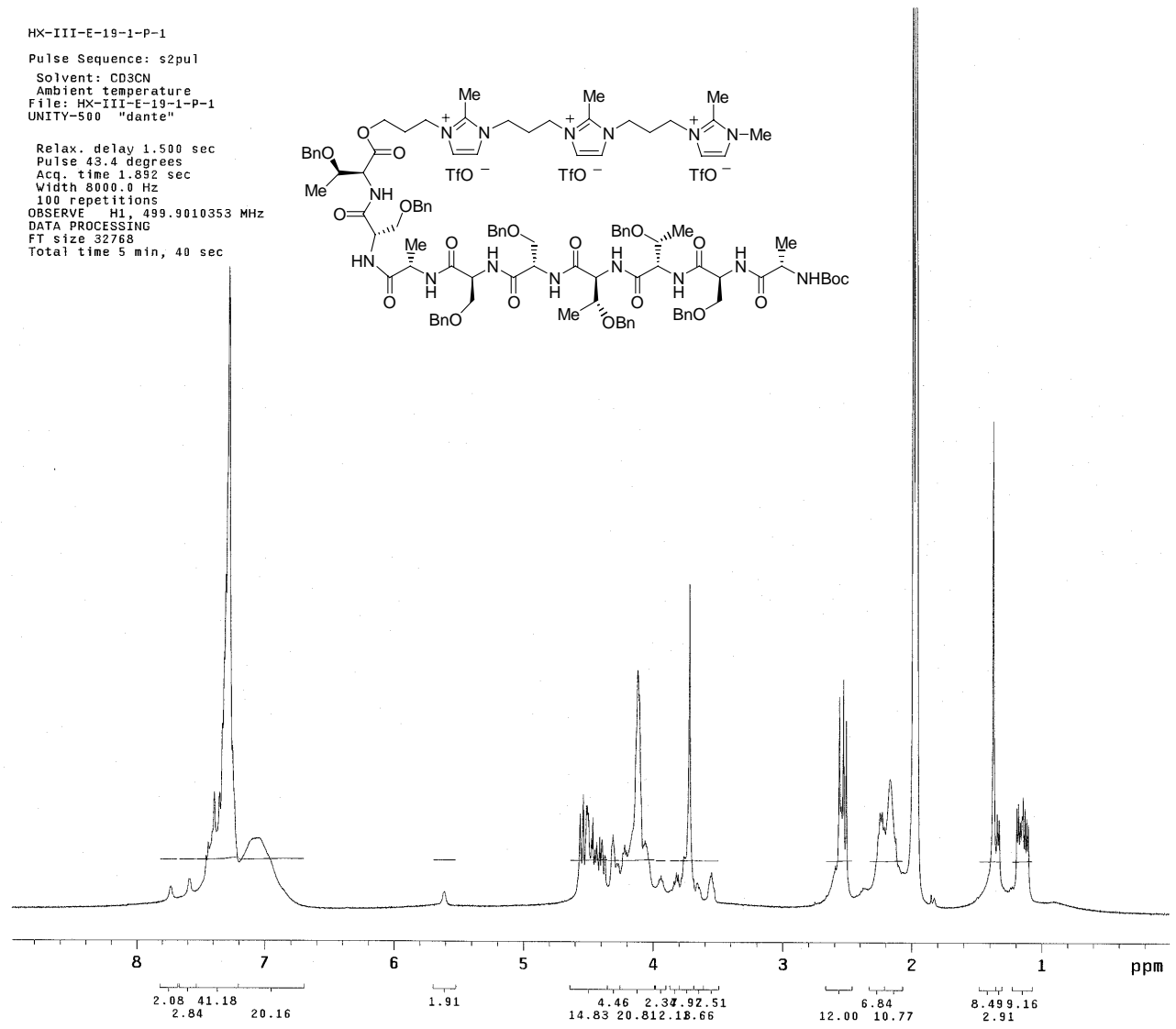

Pulse Sequence: 82 pul

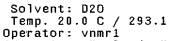

Operator: vnnr 1 1 293.1

Relax. delay $2.000 \mathrm{sec}$
Pulse 82.4 degrees
Ged

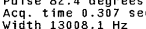

$799.7419605 \mathrm{MHz}$

TT Size 16384
Total time 1 min, $18 \mathrm{sec}$
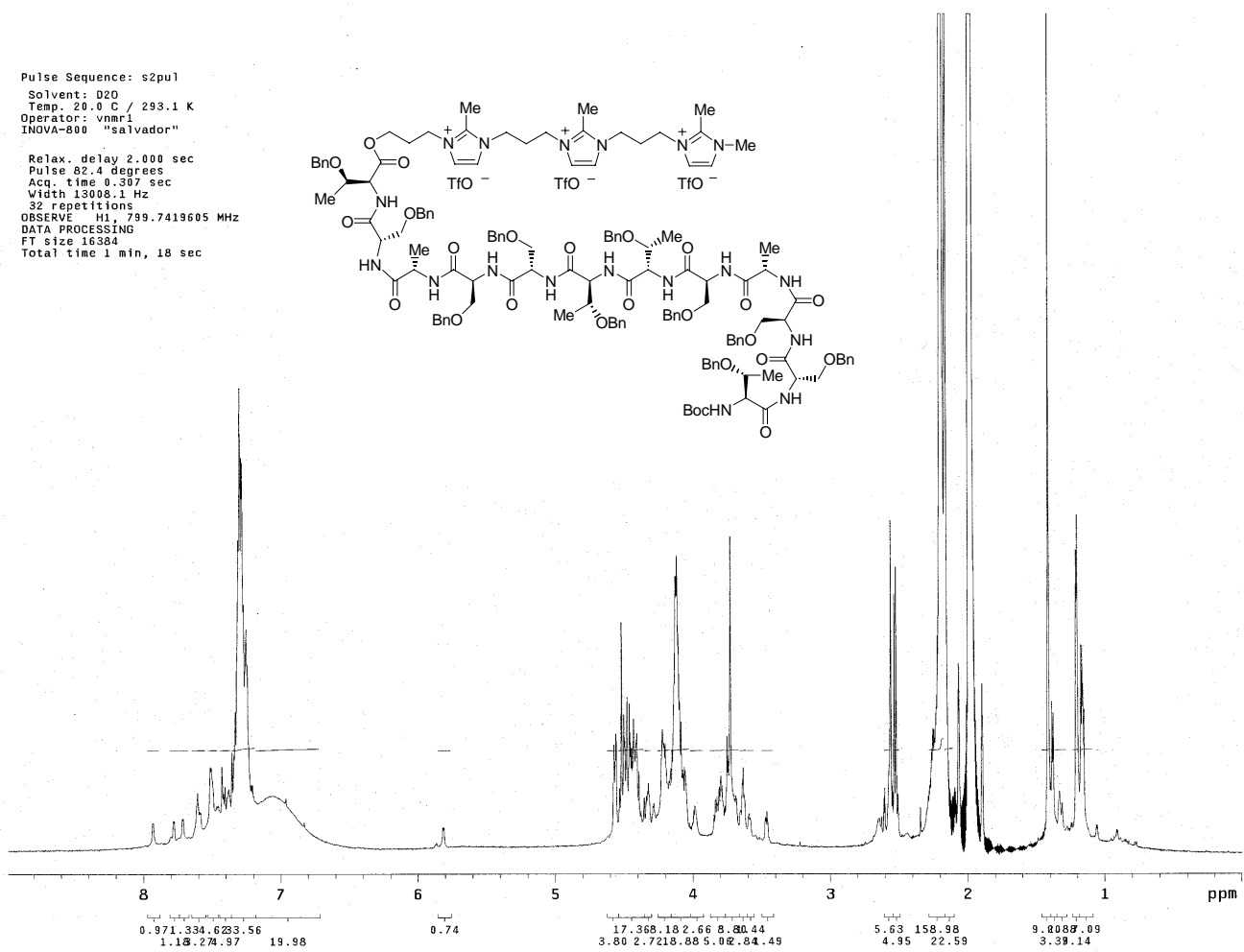


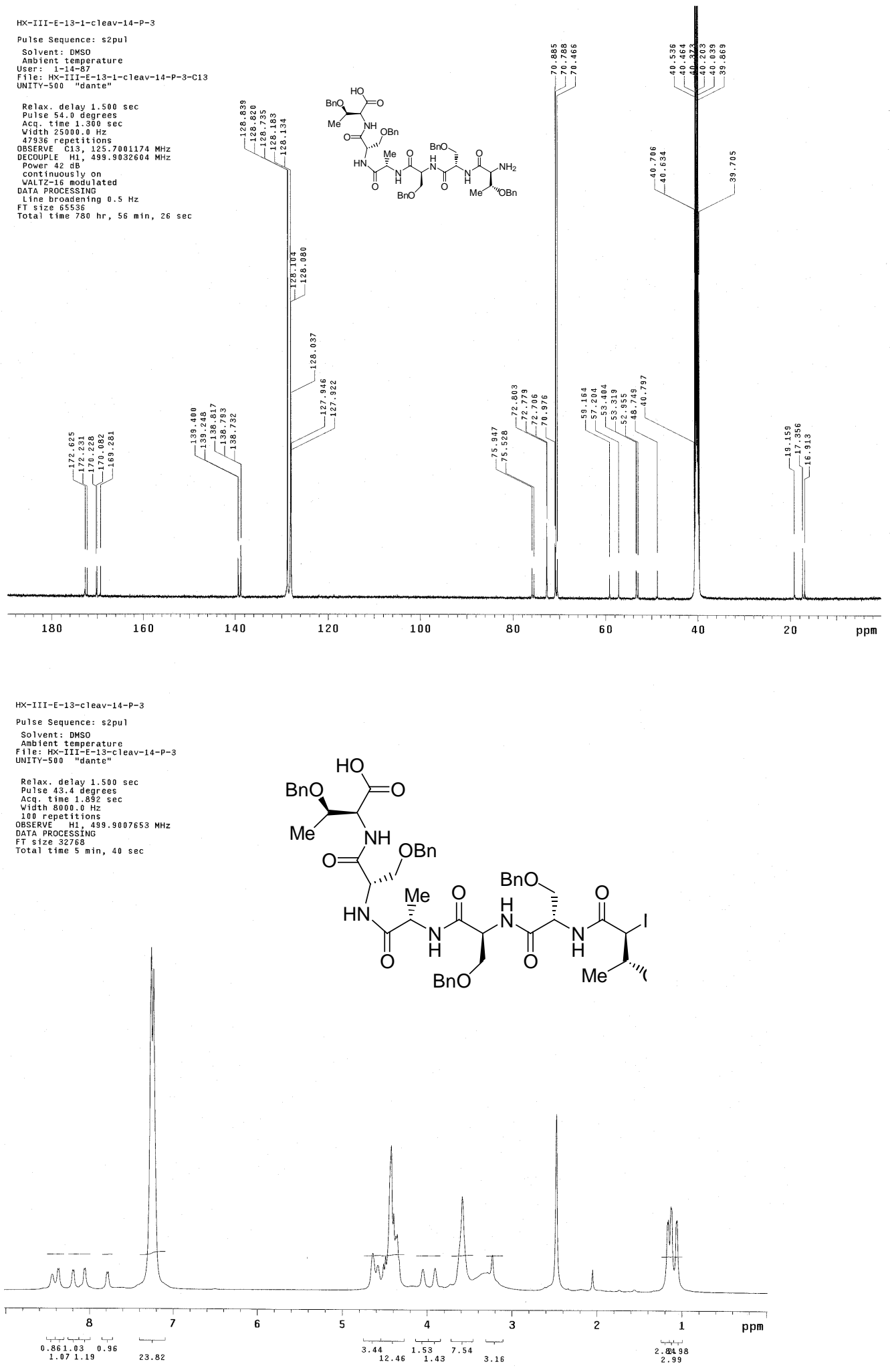



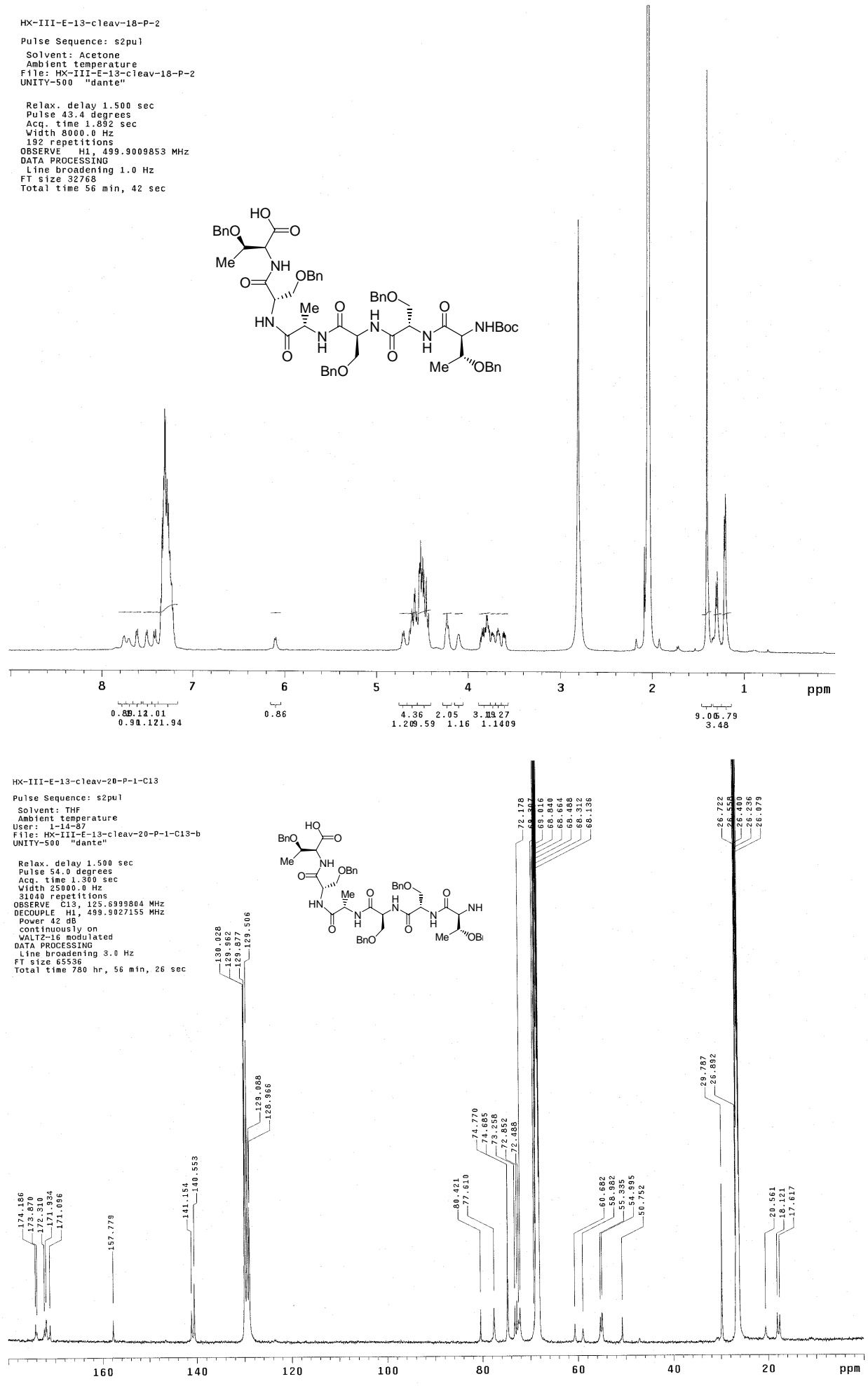


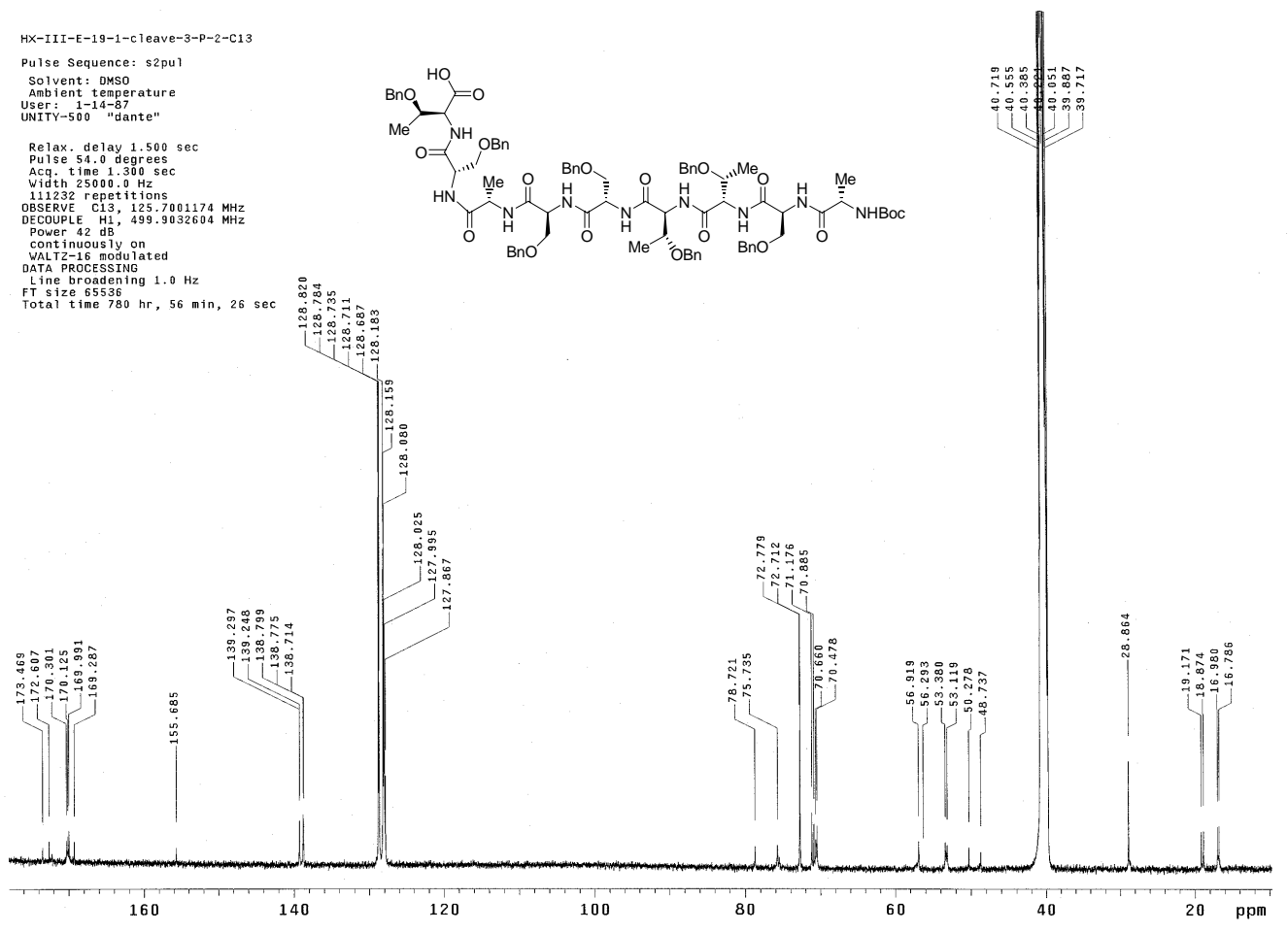

